\title{
1 Modelling water dynamics in the 2 rhizosphere
}

K.R. Daly ${ }^{1}$, L.J. Cooper ${ }^{1}$, N. Koebernick ${ }^{1}$, J. Evaristo ${ }^{2}$, S.D. Keyes ${ }^{1}$, A. van Veelen ${ }^{1}$, and T. Roose ${ }^{1}$

1Bioengineering Sciences Research Group, Faculty of Engineering and Environment, University of Southampton, University Road, Southampton S017 1BJ, United Kingdom

\author{
${ }^{2}$ Department of Natural Resources and Environmental Science, University of \\ Nevada, Reno, NV, USA \\ \$Corresponding author, krd103@soton.ac.uk
}

\section{4}

\begin{abstract}
We review the recent progress in the use of image based modelling to describe water dynamics in the rhizosphere. In addition, we describe traditional modelling and experimental methods, and how images obtained from X-ray Computed Tomography can be used in combination with direct pore-scale modelling to answer questions on water movement in the rhizosphere. The focus of this review is on the need for micro-scale experiments to parameterize image-based modelling on the pore-scale, and to show how variations in these parameters can lead to different macroscopic parameters when considering the movement of water on the plant scale. We finish the review with an illustrative example which highlights the importance of fluid-to-fluid contact angle, and the need for care in image preparation when using detailed models of this type.
\end{abstract}

\section{Key words}

Water dynamics, Rhizosphere, Image-based modelling, X-ray Computed Tomography

\section{Introduction}

The rhizosphere is defined as the region of soil over which plants have influence (Hartmann et al. 2008; Hiltner 1904). The size of this region varies depending on the precise definition used. Typical sizes range from a fraction of a millimeter, when considering microbial interactions, to tens of millimeters when considering volatile root exudates (Gregory 2006). The structural, chemical, biological and hydraulic properties of the rhizosphere are known to be significantly different to those in the surrounding bulk soil (Carminati et al. 2017; Dexter 1987; Whalley et al. 2005). 
Both plants and microbes engineer the rhizosphere in response to soil structure, water content and the availability of nutrients (Gregory 2006). Growing roots compact the soil around them resulting in a reduced porosity adjacent to the roots (Dexter 1987; Whalley et al. 2005). As they take up water plants drive wetting and drying in the soil, a process that increases soil structure formation (Grant and Dexter 1989). Roots also excrete a range of organic compounds and shed root cap cells. These rhizodeposits inhibit competition (Czarnes et al. 2000; Walker et al. 2003), and promote or inhibit microorganisms (Baetz and Martinoia 2014). Of the plant exudates, one of the most pertinent to rhizosphere water dynamics is mucilage. Secreted mucilage can form a layer that may diffuse into the rhizosphere to form a "rhizosheath" containing aggregated soil particles (Knee et al. 2001). The influence of mucilage can significantly alter the hydraulic properties of the rhizosphere (Carminati et al. 2010). Mucilage increases the area of root soil contact and thus increases the moisture supply to the plant (Yang et al. 2010). In addition, the high water-holding capacity of mucilage allows it to store up to 27 times its own mass in water (Capitani et al. 2013; Edmond Ghanem et al. 2010). As a result, mucilage can protect plant roots against diurnal soil water fluctuations, acute and osmotic stress, and the influence of saline environments (Morse 1990; Yang et al. 2010).

The role of the rhizosphere in terms of water dynamics is difficult to quantify and has been the subject of many studies (Daly et al. 2015; Downie et al. 2014; Mooney et al. 2012) and recent reviews (Carminati et al. 2016; Oburger and Schmidt 2016; Roose et al. 2016). Some studies suggest rhizosphere soil may be wetter than bulk soil (Young 1995), whilst others suggest the opposite (Daly et al. 2015). This contradiction could be due to the hydration state of the soil, i.e., in dry conditions it has been found that the rhizosphere is wetter than the surrounding soil, whilst in saturated conditions the rhizosphere has been found to be drier (Carminati 2012; Moradi et al. 2011). However, at least part of the difficulty associated with these measurements is that, from a physical perspective, it is difficult to disentangle rhizosphere soil from bulk soil.

There are a range of different dynamic processes that occur in the rhizosphere on different spatial and temporal scales. These range from fast equilibration of air-water menisci on the pore-scale, slower variations in saturation on the macro-scale, and modification of the soil structural properties on the pore scale. As all these processes influence water dynamics, it is natural to ask the question: how do processes occurring on multiple temporal and spatial scales influence water dynamics in the rhizosphere and, hence, root water uptake? In this review we focus on several key aspects of water movement in the rhizosphere and how these dynamics can be understood using image based modelling and upscaling to link different spatial and temporal scales.

Image based modelling refers to the technique of extracting geometries from, and solving equations on a series of images to predict properties. In discussing the application of these methods to the rhizosphere, we must first consider the scale on which we are working. Typically, image based models can be classified as being on the pore scale or the root scale, depending on the precise features which they resolve. On the pore scale, image based modelling can be further 
classified into network based modelling or direct modelling (Blunt 2001; Blunt et al. 2013). Pore network models are predicated on the idea that a representative pore network, consisting of pores with fixed but not necessarily cylindrical shape (Blunt 2001), can be extracted from the image instead of explicitly considering the pore scale geometry (Fatt 1956). The governing equations for fluid flow in an individual pore can then be solved in this idealized geometry, and the overall network behavior can be calculated without taking the precise details of the geometry into account. For a review see Cnudde and Boone (2013).

The alternative approach of direct modelling refers to a direct implementation of equations on geometries obtained from the images. Specifically relating to soils, image based modelling studies include, but are not limited to, flow modelling (Dal Ferro et al. 2015; Daly et al. 2015; Scheibe et al. 2015; Tracy et al. 2015), transport modelling (Daly et al. 2016; Keyes et al. 2013; Masum et al. 2016) and modelling the effects of soil compaction on Darcy flow (Aravena et al. 2010; Aravena et al. 2014). On the plant-root scale there are numerous models for water uptake, detailed in reviews by Roose and Schnepf (2008) and Vereecken et al. (2016). Spatially explicit image based models for root water uptake are relatively recent and are based on 2D imaged or idealised architectures (Doussan et al. 2006; Koebernick et al. 2015). Such models have also been realized in three dimensions based either on spatially averaged uptake terms (Dunbabin et al. 2013; Koebernick et al. 2015) or by representing the root with an explicit three dimensional boundary (Daly et al. 2017).

Whilst the focus of the review is modelling, we also discuss how soil imaging restrictions affect our understanding of rhizosphere water dynamics, and how these limitations might be overcome. In general, the multi-scale nature of the air, water and soil solid phases observed in the rhizosphere will significantly alter the description of physics in this region. Specifically, on the pore scale we observe different regions of air and water that interact and flow about the soil; on the macro-scale we see an average of these quantities described by the saturation. We will base the review around a recently developed method through which Richards' equations can be derived and parameterized based on images obtained via X-ray Computed Tomography (Daly and Roose 2015). We will review how the contact angle, surface tension, viscosity and geometry affect the macro-scale parameters in this model and discuss the implications of these observations. In addition, we will show that hydraulic properties of soils are highly sensitive to noise, image processing techniques and the physical assumptions used. This we illustrate through calculations of the water release curve and permeability for saturated and partially saturated soils.

\section{Soil water dynamics}

The more traditional mathematical models applied to study water dynamics in the rhizosphere are based on macro-scale measurements and observations. In this review we shall consider the macro-scale to be synonymous with the root or soil continuum scale. The scales we consider in this review are defined in Table 1. However, the current drive to consider how small scale features affect large scale observations means that a new generation of measurement techniques are 
required to parameterize models on the micro-scale. These measurements can then be translated across scales using mathematical upscaling methods to obtain macro-scale parameters.

In general mathematical upscaling is based on the idea that we can obtain a set of relevant macro-scale parameters by solving representative problems on the micro-scale. In this review we focus on homogenization (Pavliotis and Stuart 2008). This method allows us to not only parameterize upscaled equations, but also to derive their form based on the underlying physics. In section 2.2 we provide a detailed example of how this method works for Darcy flow. The method itself is split into three stages. Firstly, we show mathematically that the macro-scale quantities depend only on averages of the micro-scale geometry. Secondly, the microscale dependencies are determined through a set of equations solved on a representative geometry. Finally, the macro-scale equations are derived and parameterized by the micro-scale quantities through an averaging procedure. Such averages are only as good as the geometry used to solve the equations. In other words, it is only possible to model what can be seen. If heterogeneities or large macro-pores exist beyond the scale of the geometry then these cannot be accounted for and another level of averaging may be required (Daly and Roose 2014).

At first glance, this approach may seem like a very complicated way of achieving a macro-scale measurement. However, it has several distinct advantages. Firstly, it ensures that the macro-scale models are grounded in physical reality. Micro-scale models often consist of long accepted and verified mathematical descriptions that have been derived from fundamental physical principles. By combining these models with upscaling, we ensure that the macro-scale models are correct, all assumptions are clearly stated and the validity range of the macro-scale models is apparent. Secondly, this approach paves the way for optimization and design on the pore scale. For example, the effects of different geometric entities, and physico-chemical processes, can be quantified and their individual influence can be extracted.

To this end, we discuss the latest developments of imaging techniques and measurements that describe water dynamics within the rhizosphere. In addition, we show how image based modelling can serve as a link between bulk scale measurements and pore scale measurements.

\subsection{Traditional measurements}

Typically water flow in soils is described using Richards' equation (Richards 1931). Richards' equation was first independently derived by two authors, Lorenzo Richards and Lewis Richardson, in the 1920s (Knight and Raats 2016; Richards 1931; Richardson 2007). Richards' equation combines two equations. The first is an equation for water conservation in the soil

$$
\frac{\partial \phi}{\partial t}+\boldsymbol{\nabla} \cdot \boldsymbol{u}=0
$$


where $\phi$ is the pore water content (volume of water per volume of soil) and $\boldsymbol{u}$ is the total fluid flux. The second equation is Darcy's law that describes fluid flux within soil as a function of pressure gradient under the assumption that the solid matrix of soil is not moving, i.e.,

$$
\boldsymbol{u}=-K(\phi) \nabla p
$$

where $p$ is the pore water pressure and $K(\phi)$ is the saturation dependent hydraulic conductivity. Substituting (2) into (1), we obtain the mixed form of Richards' equation for partially saturated flow

$$
\frac{\partial \phi}{\partial t}=\boldsymbol{\nabla} \cdot[K(\phi) \nabla p]
$$

Equation (3) is a dynamic equation, which is traditionally parameterized by two equilibrium measurements. In addition to the hydraulic conductivity, the second measurement required to complete Richards' equation is the Water Retention Curve (WRC). This describes the relationship between water content $\phi$ and pore water pressure (or matric potential) $p$. This is usually acquired by fitting a sigmoid curve to a set of experimental data that measures the rate of change of soil saturation in response to the changes in matric head. The WRC is dependent on soil structure, texture, and morphological properties, see Vereecken et al. (2010) and references therein. In addition, the soil wetting curve significantly differs from the soil drying response, giving rise to wetting-drying hysteresis. This hysteresis also changes when wetting is stopped at different points leading to different "scanning curves" between wetting and drying curves. In other words the hysteresis depends not only on whether the soil is wetting or drying, but also on the saturation at which wetting/drying started. Often, instead of using direct measurement, the water retention is obtained from a set of theoretical curves (Vereecken et al. 2010); the most popular forms of which are the van Genuchten-Mualem models (Mualem 1974; 1976a; b; Van Genuchten 1980) and the Brooks and Corey model (Brooks and Corey 1964).

In order to measure the WRC it is necessary to either hold the water content constant and measure the matric potential, or to hold the matric potential constant and measure the water content. Techniques for matric potential determination and water content measurement are varied, with the preferred method depending on a host of factors including measurement range, accuracy, spatial resolution and scales of interest. Measurement and modeling of water flow in soils, across a range of spatial and temporal scales, has been acknowledged as an enduring scientific grand challenge (Hopmans and Schoups 2005; Philip 1980). Hence, due to the non-unique and scale-dependent nature of the problem, the ability to predict water flow in soils, let alone the rhizosphere, continues to be limited by the techniques for making measurements at the appropriate scale.

At the regional and global scales, microwave remote sensing on board satellites is the primary technique for soil water content measurement (Bittelli 2011; Njoku et al. 2003). This technique uses either passive or active measurements 
(Wigneron et al. 2003), and is based on the assumption that the dielectric constant of soil increases with water content, see the reviews by Wagner et al. (2007) and De Jeu et al. (2008). At the field and watershed scales, geophysical methods (electrical resistivity and ground penetrating radar) and airborne remote sensing (using microwave sensors) provide a cost-effective and nonlabor-intensive way to measure soil water content (Robinson et al. 2008a).

On the plant scale, in-situ measurements may be categorized as either direct or indirect. The only technique that directly measures soil water content is the gravimetric technique (Robock et al. 2000; Vinnikov and Yeserkepova 1991), in which field soil samples are weighed before and after drying, thereby deriving soil water content from a change in mass. However, the destructive and labor intensive nature of this technique makes it irreproducible and, in many instances, cost-prohibitive. Notwithstanding, gravimetric measurements continue to serve as reference measurements for calibrating indirect in-situ techniques. There are two commonly used indirect in-situ measurements of soil water content: time domain reflectometry (Robinson et al. 2008b; Topp and Reynolds 1998) and soil capacitance (Dean et al. 1987; Robinson et al. 2008b). These techniques are both predicated on the fact that soil dielectric permittivity depends on soil water content. The less commonly used indirect in-situ techniques are neutron probes (Hollinger and Isard 1994; Robinson et al. 2008b), electrical resistivity, heat pulse and fiber optic sensors, and gamma ray scanners (Hillel 1998; Robinson et al. 2008b; Robock et al. 2000).

On the pore scale, the complexity of the rhizosphere combined with the opaque nature of soil has led a growing number of groups utilizing X-ray Computed Tomography (X-CT), and either 2D Neutron Radiography (NR) or 3D Neutron Tomography (NT) to directly visualize the rhizosphere and its water fraction. Both X-CT and NT are based on repeated imaging of soil samples at different angles. By combining these images, a three dimensional visualization of the soil can be obtained. The specific influence of soil and root structures on soil hydrodynamics has been investigated using benchtop X-CT at a number of scales (Aravena et al. 2010; Aravena et al. 2013; Carminati et al. 2009; Koebernick et al. 2015; Ngom et al. 2011; Tracy et al. 2015). In addition, Synchrotron X-CT beamlines permit fine structures such as root hairs and soil micro-pores to be extracted in 3D from reconstructed data (Daly et al. 2016; Keyes et al. 2013; Nestler et al. 2016; Peth et al. 2008; Yu et al. 2017). X-CT and NT studies are not without their limitations. In both cases there is a tradeoff between resolution and the total field of view, which is typically 3 orders of magnitude larger than the resolution (Roose et al. 2016). Synchrotron radiation X-CT has been demonstrated down to resolutions approaching $\sim 100 \mathrm{~nm}$ (Stampanoni et al. 2010), however, the corresponding field of view of $\sim 100 \mu \mathrm{m}$ is two orders of magnitude smaller than the rhizosphere length scale. The resolution for NT is typically two orders of magnitude worse than for X-CT (Roose et al. 2016).

In certain scenarios, fluid transport in porous media can be visualized by X-CT methods (Berg et al. 2013). For direct in situ imaging of water distribution and transport in soils, NR and NT have become the standard techniques (Carminati et al. 2010; Esser et al. 2010; Menon et al. 2007; Oswald et al. 2008; 
Zarebanadkouki et al. 2012). NR has enabled in-situ measurements of the WRC (Kang et al. 2014), and soil water profiles around roots to be quantified during drying and rewetting, allowing determination of radial hydraulic conductivity (Zarebanadkouki et al. 2016), and the use of deuterated water $\left(\mathrm{D}_{2} \mathrm{O}\right)$ as a complementary tracer has also allowed quantification of water uptake heterogeneity among root types (Ahmed et al. 2016). Recently NR has also been used to quantify root growth and uptake properties for plants recovering from drought with significant hydraulic redistribution observed (Dhiman et al. 2017).

Unlike bulk soil water content measurement techniques, soil matric potential measurements continue to be limited to averaged measurements over a small volume of soil, which may be comparable with the size of the rhizosphere. Appropriate methods generally depend on the soil moisture range, with suction ranges for tensiometry, reference porous media (e.g. gypsum blocks), and thermocouple psychometry being suitable for moist $\left(10^{-1}-10^{2} \mathrm{kPa}\right)$, intermediate moist $\left(10^{1}-10^{5} \mathrm{kPa}\right.$ ), and relatively dry $\left(10^{5}-10^{8} \mathrm{kPa}\right)$ soils respectively (Durner and Or 2005). In addition pressure plates can be used for intermediate moist region $\left(10^{1}-10^{3} \mathrm{kPa}\right)$ (Smith 2000).

Despite the advances in water content measurements across scales, water dynamics in the rhizosphere is sometimes described inferentially via indirect methods to infer root water uptake at point (e.g. sap flow) and field scales (e.g. eddy covariance). The sap flow method derives high frequency estimates of water flow through stems based on changes in thermal properties (Granier 1985). Its main drawback is in scaling measurement data from sap flow to the plant and ecosystem scales. The eddy covariance method provides continuous estimates of evapotranspiration for a relatively large area using high-frequency measurements of momentum, temperature, and water vapor (Brutsaert 1982). However, deriving transpiration dynamics using this method continues to be a challenge (Kool et al. 2014).

One method, which has implications for pore-scale modelling is the use of waterstable isotopes in plant-soil-water studies. This approach is predicated on the assumption that root water uptake is generally a non-fractionating process (Dawson and Ehleringer 1991). That is, the isotopic composition of xylem water represents an integrated signal of its sources within the rhizosphere. Indeed, isotope methods have led to an improved understanding of where plants derive their water at field (Ehleringer and Dawson 1992; Evaristo et al. 2016; Zhang et al. 2016b), watershed (Berkelhammer et al. 2016; Thorburn et al. 1993), regional and global scales (Evaristo and McDonnell 2017; Good et al. 2015). Recently, it has been suggested that plant transpiration is supplied by water held under capillary pressure, whilst local streams and groundwater are supplied by more mobile sources such as infiltration due to precipitation (Evaristo et al. 2015).

\subsection{Image based modeling}

We have discussed how different experimental techniques can be used to measure the water retention curve on both the pore scale and the bulk scale. An important technique which links these scales and provides the means to measure soil moisture properties in-silico is homogenization. In its most basic form, 
homogenization is a mathematical tool which enables spatial averaging (Cioranescu and Donato 1999; Pavliotis and Stuart 2008). Homogenization is generally used in (but not limited to) problems which exhibit an underlying periodic structure either physically or in terms of the functions used to parameterize the models. Hence, it is particularly well suited to porous media problems (Hornung 1997). Homogenization can be used to derive numerous bulk scale properties including; permeability (Keller 1980; Tartar 1980), effective diffusion coefficient (Zygalakis et al. 2011; Zygalakis and Roose 2012), isotropic and anisotropic poro-elastic properties (Burridge and Keller 1981; Lee and Mei 1997) and the water release characteristic (Daly and Roose 2015).

with

The key observation used in homogenization is that variations on the bulk scale correspond to small changes on the pore scale. As an example we consider the averaging of Stokes' equation in a homogeneous soil. We assume that the soil is described by a fluid filled pore space which we denote $\Omega$, with a soil solid boundary $\Gamma$. In the porespace the fluid is assumed to move at sufficiently low Reynolds number that we may neglect the inertial terms in the Navier Stokes equations. Hence, we consider the Stokes equations

343

344

$$
\begin{gathered}
\eta \nabla^{2} \boldsymbol{u}-\nabla p=0 \\
\boldsymbol{\nabla} \cdot \boldsymbol{u}=0
\end{gathered}
$$

$\mathbf{x} \in \Omega$, $\mathbf{x} \in \Omega$,

$$
\boldsymbol{u}=0
$$$$
\mathbf{x} \in \Gamma,
$$

where $\mathbf{u}$ is the fluid velocity, $p$ is the pore water pressure, $\eta$ is the viscosity, $\boldsymbol{\nabla}=\left(\partial_{\tilde{x}_{1}}, \partial_{\tilde{x}_{2}}, \partial_{\tilde{x}_{3}}\right)$ is the vector gradient operator, and $\tilde{x}_{1}, \tilde{x}_{2}, \tilde{x}_{3}$ are the spatial coordinates. We consider a sample of homogeneous soil with typical length scale $L_{x}$ containing a uniform distribution of soil particles with typical size $L_{y}$. We are interested in determining the fluid velocity driven by a pressure drop of size $[p]$ over a distance $L_{x}$. This naturally leads to two possible velocity scales, $\widetilde{\boldsymbol{u}}=$ $\left[u_{x}\right] \boldsymbol{u}$, where $\left[u_{x}\right]=\frac{L_{x}^{2}}{\eta} \frac{[p]}{L_{x}}$ and $\widetilde{\boldsymbol{u}}=\left[u_{y}\right] \boldsymbol{u}$, where $\left[u_{y}\right]=\frac{L_{y}^{2}}{\eta} \frac{[p]}{L_{x}}$. These two choices of scaling have different physical interpretations. The former describes the velocity impeded by obstacles of typical size $L_{x}$ whilst the latter describes fluid velocity impeded by obstacles of the size $L_{y}$. Mathematically we could choose either of these options and we would find that the resulting expression for velocity is the same. However, as we are considering obstacles of size $L_{y}$, we choose $\widetilde{\boldsymbol{u}}=\left[u_{y}\right] \boldsymbol{u}$, which results in a simplified analysis.

We now move on to find the average velocity driven by a pressure gradient $\frac{\delta p}{\delta x}=\frac{[p]}{L_{x}}$ for a flow which is impeded by obstacles on the scale $L_{y}$. The key assumption required is that a pressure drop of size 1 over the length scale $L_{x}$ is equal to a pressure drop of size $\epsilon=L_{y} / L_{x} \ll 1$ over a distance $L_{y}$. To formalize this we can introduce the idea of two different dimensionless spatial scales, the small scale $\boldsymbol{y}=\left(y_{1}, y_{2}, y_{3}\right)=\left(\tilde{x}_{1}, \tilde{x}_{2}, \tilde{x}_{3}\right) / L_{y}$, and the large scale $\boldsymbol{x}=\left(x_{1}, x_{2}, x_{3}\right)=$ $\left(\tilde{x}_{1}, \tilde{x}_{2}, \tilde{x}_{3}\right) / L_{x}$. In order that the system of equations is well posed we assume that the pressure can be written as $p=p_{0}+\epsilon p_{1}+O\left(\epsilon^{2}\right)$, where $p_{0}$ is the applied pressure drop and $p_{1}$ is the localized pressure variation due to the geometrical 
372 with

373

with

impedance which is of size $\epsilon$. The notation $O\left(\epsilon^{2}\right)$ refers to terms of size $\leq \epsilon^{2}$, i.e., we have neglected terms smaller than size $\epsilon$ in our analysis. Hence, we can write $\boldsymbol{\nabla}=\epsilon^{-1} \boldsymbol{\nabla}_{\boldsymbol{y}}+\boldsymbol{\nabla}_{\boldsymbol{x}}$, where $\boldsymbol{\nabla}_{x}$ and $\boldsymbol{\nabla}_{y}$ are the gradient operators on the bulk and pore scale respectively. Substituting into equations (4), (5), and (6) we obtain

$$
\begin{array}{cc}
\nabla_{y}^{2} \boldsymbol{u}-\nabla_{\boldsymbol{y}} p_{1}-\nabla_{x} p_{0}-\epsilon^{-1} \nabla_{\boldsymbol{y}} p_{0}=O(\epsilon), & \mathbf{x} \in \Omega, \\
\boldsymbol{\nabla}_{\boldsymbol{y}} \cdot \boldsymbol{u}+\epsilon \boldsymbol{\nabla}_{\boldsymbol{x}} \cdot \boldsymbol{u}=O(\epsilon), & \mathbf{x} \in \Omega,
\end{array}
$$

$$
\boldsymbol{u}=0, \quad \mathbf{x} \in \Gamma .
$$

If we consider only the dominant terms in equation (7), i.e., those with a prefactor $\epsilon^{-1}$, we find

$$
\nabla_{\boldsymbol{y}} p_{0}=0, \quad \quad \mathbf{x} \in \Omega \text {. }
$$

Hence, $p_{0}$ is independent of $\boldsymbol{y}$ and, on the small scale, pressure can vary by an amount less than $\epsilon$. We note that this equation does not define $p_{0}$; all we can conclude is that $p_{0} \sim p_{0}(\boldsymbol{x})$, i.e., the dominant pressure drop occurs on the long length scale. Implicit in equation (10) is the observation that the soil structure is periodic, i.e., it is composed of regularly repeating unit cells. This assumption is clearly not true for soil samples and will be considered later.

To proceed we must consider the terms we have neglected. We assume that a large scale pressure gradient $\nabla_{x} p_{0}$ can induce a small velocity and pressure on the pore scale, i.e.,

$$
\begin{gathered}
\boldsymbol{u}=\boldsymbol{\kappa}_{\boldsymbol{k}}(\boldsymbol{y}) \hat{\boldsymbol{e}}_{\boldsymbol{k}} \cdot \nabla_{\boldsymbol{x}} p_{0}(\boldsymbol{x}, t)+O(\epsilon), \\
p=p_{0}(\boldsymbol{x})+\epsilon \omega_{k}(\boldsymbol{y}) \hat{\boldsymbol{e}}_{\boldsymbol{k}} \cdot \nabla_{x} p_{0}(\boldsymbol{x}, t)+O\left(\epsilon^{2}\right),
\end{gathered}
$$

where $\boldsymbol{\kappa}_{\boldsymbol{k}}(\boldsymbol{y})$ and $\omega_{k}(\boldsymbol{y})$ are the local velocity and pressure coefficients respectively. Using this assumption we can collect the largest terms in equations (7) and (8) to obtain

$$
\begin{array}{cc}
\nabla_{y}^{2} \boldsymbol{\kappa}_{\boldsymbol{k}}-\boldsymbol{\nabla}_{\boldsymbol{y}} \omega_{k}=\hat{\boldsymbol{e}}_{k}, & \mathbf{x} \in \Omega, \\
\boldsymbol{\nabla}_{\boldsymbol{y}} \cdot \boldsymbol{\kappa}_{\boldsymbol{k}}=0, & \mathbf{x} \in \Omega,
\end{array}
$$

$$
\boldsymbol{\kappa}_{k}=0, \quad \quad \mathbf{x} \in \Gamma .
$$

Equations (13), (14) and (15) are referred to in the homogenization literature as a cell problem. This cell problem is solved in a representative unit volume of soil and the results are used to determine the bulk scale flow properties of the soil.

The final stage of the homogenization procedure is to substitute equations (11) and (12) into equations (8) and (9) before enforcing the requirement that the resulting equation has a solution. We omit the details here and refer the reader to Hornung (1997), Daly et al. (2015), and Tracy et al. (2015) for details. The result is an equation which captures the Darcy flow of water on the large scale. In dimensional form this is written as 
where

$$
\boldsymbol{\nabla} \cdot \boldsymbol{u}=0
$$

$$
\boldsymbol{u}=-\frac{\boldsymbol{K}}{\eta} \boldsymbol{\nabla} p_{0}(\boldsymbol{x})
$$

407 is the Darcy velocity and

$$
K=L_{y}^{2} \int_{\Omega} \kappa_{k} \otimes \hat{e}_{k} d \Omega
$$

is the permeability, which is parameterized by the underlying soil structure. The symbol $\otimes$ denotes the tensor product (Abramowitz and Stegun 1964). Equations (16) to (18) combined with the cell problem (13) to (15) provides a direct link between the micro-scale physical and geometrical properties of saturated soil and the macro-scale description and parameterization.

\section{The effect of soil properties on rhizosphere water dynamics}

Before we describe how image based modelling can be extended to partially saturated flow in the rhizosphere we consider how changes in soil parameters affect porosity, permeability and the water release curve. These parameters can all be influenced by plants and plant exudates such as mucilage (Aravena et al. 2010; Carminati et al. 2017; Carminati et al. 2016; Koebernick et al. 2017; Naveed et al. 2017).

\subsection{Surface tension and viscosity}

The effects of surface tension and viscosity have been recently reviewed by Carminati et al. (2017), for completeness we briefly summarize their effects here. In the rhizosphere the surface tension can be altered by plant exudates (Read and Gregory 1997) and bacteria that produce bio-surfactants. Mohammed et al. (2014) showed that bacterial bio-surfactants could lower the surface tension of the air-water interface from $72.86 \times 10^{-3} \mathrm{~N} \mathrm{~m}^{-1}$ to $25 \times 10^{-3} \mathrm{~N} \mathrm{~m}^{-1}$ at $20^{\circ} \mathrm{C}$.

Bacteria and plant exudates have been shown to affect the viscosity of soil water, which impacts on rhizosphere water dynamics (Naveed et al. 2017; Yegorenkova et al. 2013). At low concentrations $0.7 \mathrm{mg} \mathrm{g}^{-1}$ the viscosity is already twice that of pure water (Read and Gregory 1997) and at higher concentrations $10 \mathrm{mg} \mathrm{g}^{-1}$ the viscosity reaches concentrations $\approx 1000$ times that of pure water (Ahmed et al. 2016).

\subsection{Geometry}

One of the most visually obvious effects of plant roots on the rhizosphere is that of soil compression (Dexter 1987; Whalley et al. 2005). Roots expand and compact the soil around them resulting in a noticeable structural variation (Koebernick et al. 2017). Models can directly visualize this effect through images captured using X-CT. Typically image based models are based on a computational mesh generated directly from segmented images (Daly et al. 2016; Keyes et al. 2015; Koebernick et al. 2017). In addition, root hairs and mycorrhizal fungi can, in theory, be visualized on this scale (Keyes et al. 2013), although this has not yet been achieved in the case of mycorrhizal fungi. The effect of these small scale filamentous structures on water dynamics is difficult to 
quantify and will be strongly dependent on their wettability. If these structures are strongly hydrophilic they could form bridges between the root and water held at high matric potential in the smallest pores, resulting in a dramatically increased water uptake.

In order to parameterize image based models, X-CT data must first be reconstructed to produce 3D grey-scale images, i.e., structured regular arrays in which the value of each element is proportional to the local X-ray attenuation at the corresponding point in space. The 3D structure of soil is required as water and air phases are likely to be disconnected in 2D. It is only once the full 3D picture is known that the connectivity of the soil pore space can be accurately characterised, of course the parameters can then be applied in lower dimensional models, assuming appropriate symmetries. Once reconstructed, the data can be processed to extract specific features as discrete regions, or clusters of voxels (Houston et al. 2013), a step known as segmentation. This step is highly significant, as it influences all further analyses (Schlüter et al. 2014; Kaestner, Lehmann, and Stampanoni 2008). As such, the methods used are relevant to image based modelling. The challenges in segmenting soil X-CT data have been recently reviewed by a number of authors (Cnudde and Boone 2013; Houston et al. 2013; Mooney et al. 2012; Roose et al. 2016; Schlüter et al. 2014), and are outlined in brief here.

Two broad families of segmentation approaches exist: global thresholding methods and locally adaptive methods. Global thresholding methods assign voxels to classes using only the grey-level histogram of the image, and thus do not take into account local voxel statistics (Sezgin 2004). Locally adaptive methods consider the local neighbourhood of each voxel during class assignment, with statistical descriptors often providing substantial discriminatory power (Schlüter et al. 2014).

Two of the best known global thresholding methods are the maximum variance filter (Otsu 1979), which minimises in-class variance whilst maximising between-class variance, and the minimum error filter (Kittler and Illingworth 1986), which defines thresholds as the intersections of Gaussians fitted to each class. Histogram-based segmentation methods are computationally inexpensive. However, as they are only based on global information they are prone to misclassification errors. This has led them mostly to be used as an efficient means to initialise classes for refinement by more complex locally adaptive filters (Kaestner et al. 2008).

Locally adaptive approaches use the neighbourhood of each voxel to smooth feature edges, suppress noise artefacts, and reduce the effect of local intensity variance (Schlüter et al. 2014). Examples of commonly used locally adaptive approaches are region growth (Schlüter, Weller, and Vogel 2010; Keyes et al. 2013; Vogel and Kretzschmar 1996), which effectively operates as a seed-based 'flood fill' connectivity operator; indicator kriging, a spatially-explicit class minimisation approach (Oh and Lindquist 1999; Alasdair N Houston et al. 2013); watershed segmentation, which separates classes along lines ('watersheds') of highest gradient (Roerdink and Meijster 2000; Schlüter et al. 2014); and the 
WEKA segmentation approach, which uses machine-learning to classify voxels based on a suite of image measures and a user-defined training dataset (Hall et al. 2009; Arganda-Carreras, I., Cardona, A., Kaynig, V., Schindelin 2014). By incorporating local information adaptive methods can provide good segmentations where global methods fail (Kaestner et al. 2008; Schlüter et al. 2014).

Whichever method is used, the result is a 3D image in which the grey level determines the phase of the material at that point in space. Typically, the next step in image based modelling is to produce a computational mesh, which conforms to the geometry in the image and enables the implementation of numerical schemes to solve the cell problems.

At this point we need to return to the assumptions used to derive Richards' equation using homogenization. A key assumption used was that the geometry is periodic and the representative properties of the soil can be captured from a single representative unit cell. However, in general soil structure is not periodic. Hence, in order to make the theory in section 2.2 applicable, periodicity has to be enforced. There have been a range of different approaches to doing this in the literature. In general there are three approaches which could be taken; periodicity can be enforced by (1) translation, or (2) reflection of the geometry in the $x, y, z$ axes, see Figure 1. Alternatively, (3) boundary conditions can be applied on the outside of the domain which mimic those applied on the soil particle surfaces, in the case of water flow these would take the form of either no slip or slip conditions.

Method (1) has the advantage that it captures soil properties without the need to make simplifying assumptions on the geometry. It has the distinct disadvantage that it introduces a jump discontinuity in the soil structure, Figure 1a. Methods (2) and (3) are somewhat similar in their approach, and in the case of most equations will result in the same boundary conditions. What differs is the interpretation of the results. Method (2) involves little alteration of the soil geometry. However, if taken in the strictest sense then it eliminates any off axis anisotropy in the system. A geometry which is mirrored in all coordinate axes is by definition aligned with the principle anisotropic axes. Hence, any off diagonal components calculated in the effective tensors must be equal and opposite to the value of those components in the reflected part of the geometry. Alternatively, using method (3) any off diagonal components in the effective tensor are counted in the total anisotropic tensor and the only problem that occurs is that the soil properties are not accurately calculated at the edge of the domain. This problem can easily be overcome by considering successively larger geometries until the properties of the fluids converge (Bear 2013; Tracy et al. 2015).

\subsection{Contact angle}

In addition to the compaction effects of roots, root exudates can alter the chemical properties of the rhizosphere (Gregory 2006; Naveed et al. 2017). In particular, this has the effect of altering the wettability of soils through the airwater contact angle. It is well known that the wettability of soils in the 

Carminati et al. 2010; Moradi et al. 2011; Roose et al. 2016; Schwartz et al. 2016). However, the precise nature of how micro-scale parameters affect wettability is still unclear. In the Young-Laplace equation the capillary pressure is linearly related to $\cos \theta$, where $\theta$ is the contact angle, and works well for single idealised pores. A $0^{\circ}$ contact angle indicates that the soil particles are fully wetted and is a common assumption in soil physics. Mathematical and numerical modelling studies often indicate that using a $0^{\circ}$ contact angle gives results that are most accurate when compared to experimental data (Cooper et al. 2017; Pot et al. 2015; Schaap et al. 2007).

The contact angle is influenced by a series of factors including hysteresis, whether the soil is wetting, drying or at equilibrium (Kusumaatmaja and Yeomans 2010); surface roughness (Czachor et al. 2013); organic matter content (Czachor et al. 2013); and the plane in which the contact angle is measured (Andrew et al. 2014). The method used to measure the contact angle can affect results, with variations as high as $25^{\circ}$ measured for the same sample (Shanga et al. 2008). Finally, we note that a further complication of determining the contact angle is the scale at which the angle is measured; we classify these as macroscale, micro-scale and nano-scale methods in the context of rhizosphere research, see Table 1.

On the macro-scale, various methods exist to measure the contact angle, most of which are large-scale measurements. The sessile drop method is based on placing a fluid drop of known volume onto a surface; the contact angle is then measured visually. The Wilhelmy plate method uses a plate coated with soil that is lowered into a liquid surface. The force required to lower the plate into the liquid is measured and used to calculate the surface tension or contact angle. Finally, the column wicking method refers to the use of a capillary rise experiment; the contact angle is calculated from the speed of capillary rise. A brief description of these methods can be found in Shanga et al. (2008). On the micro-scale, X-CT has been used to measure contact angles in a carbonate-brine$\mathrm{CO}_{2}$ system (Andrew et al. 2014) and for distilled water in glass beads (Manahiloh and Meehan 2017). On the nano-scale, molecular dynamic models have also been used to investigate contact angles. Lukyanov and Likhtman (2016) found that the contact line force is determined from a nonlinear friction law and local density and velocity distributions. Zhang et al. (2016a) applied a molecular dynamics model to three common soil minerals, $\alpha$-quartz, orthoclase and muscovite, calculating contact angles of $29^{\circ}, 36^{\circ}$ and $116^{\circ}$, respectively.

Of these methods the most commonly used are the macro-scale methods. Whilst these methods are useful, they are fundamentally large scale, less accurate methods and involve inferring a contact angle on a rough surface based on the assumption that it is planar. Hence, the calculated contact angle will be different to that observed on the micro-scale (Buckton et al. 1995); see Figure 2. As a result, it is difficult to parameterize image based models directly from results obtained in the literature; a particularly important factor in the rhizosphere where soil properties are known to be different from bulk soil. 


\section{Illustrative example}

We now consider an illustrative example that highlights the importance of soil properties in the rhizosphere and how its effects can be captured and upscaled using image based modelling. As illustrated for single phase flow in section 2.2, the method of homogenization provides a link between what we observe on the micro-scale and what is measured and observed on the macro-scale. In order to link macro-scale flow properties and observations to the physical parameters and measurements on the micro-scale, two of the authors have recently extended this method to consider variably saturated soil (Daly and Roose 2015). This approach enables the estimation of the WRC and partially saturated hydraulic parameters using geometries obtained directly from X-CT images of soil structure. We will use this method to illustrate how the contact angle, surface tension, viscosity and geometry affect soil water dynamics and, hence, will shed light on how water dynamics in the rhizosphere differs from bulk soil.

\subsection{The mathematical model}

We start by briefly summarizing the derivation of Richards' equation using homogenization (Daly and Roose 2015). The starting point is a model for two fluid flow in partially saturated soil using a combination of the Cahn-Hilliard equations and Stokes' equation (Anderson et al. 1998), under the assumption that capillary forces dominate water movement. The Cahn-Hilliard equations describe how two fluids separate into two domains by minimizing the surface area between the two fluids. The Stokes' equation describes low Reynoldsnumber flow where nonlinear terms can be neglected; this is assumed to be the case in micro-scale soil pores. Under the assumption that the air phase is at constant pressure and is stationary, Richards' equation derived by homogenization in dimensional form is,

$$
\|\Omega\| \frac{\partial S}{\partial t}-\boldsymbol{\nabla} \cdot\left[\frac{K(S)}{\eta} \cdot\left(\frac{\delta p}{\delta S} \nabla S+g \rho \hat{\boldsymbol{e}}_{3}\right)\right]=0,
$$

where $S$ is the saturation, $p$ is the capillary pressure, $\eta$ is the viscosity of water, $\rho$ is the density of water, $\|\Omega\|$ is the porosity, $t$ is time, $\nabla$ is the gradient operator, and $g$ is the gravitational acceleration. $K(S)$, and $\frac{\delta p}{\delta S}$ are parameters calculated from the cell problems, see Daly and Roose (2015) for full details. The first cell problem directly captures the WRC by fixing saturation or capillary pressure and numerically calculating the other, which involves directly evaluating the position of the air-water interface based on the assumption that capillary forces dominate the water dynamics.

In Daly and Roose (2015) the authors took the approach of fixing the saturation and calculating the required capillary pressure. For the illustrative examples in the next section we take the opposite approach and rewrite the equations from Daly and Roose (2015) under the assumption of fixed capillary pressure as this is closer to the experimental protocol, see section 2.1. We define the fluid phase variable $\varphi$, which takes value 1 in the water phase and 0 in the air phase. The air-water interface can be found by solving 


$$
\frac{\partial \varphi}{\partial t}=\lambda \nabla^{2} \varphi-\frac{f^{\prime}(\varphi)}{\lambda}+\mu,
$$

with the boundary condition

$$
\widehat{\boldsymbol{n}} \cdot \nabla \varphi=|\nabla \varphi| \cos (\theta)
$$

$\mathbf{x} \in \Gamma$

on the soil geometry rescaled to have sides of unit length. Here $\theta$ is the contact angle,

$$
\mu=\frac{L_{y}}{6 \sqrt{2} \gamma} p
$$

is the scaled capillary pressure, $\gamma$ is the surface tension, $L_{y}$ is the side length of the soil geometry, $f(\varphi)$ is a fluid energy chosen based on observations of fluidfluid interaction. $f(\varphi)$ is minimized if $\varphi$ takes values of 1 or 0 , and $\lambda$ is an interface thickness which is chosen as being small compared to the smallest feature of interest in the image. The contact angle boundary condition, equation (21), is simply a statement of the cosine rule as $\frac{\nabla \varphi}{|\nabla \varphi|}$ is a vector normal to the airwater interface. This representation is somewhat different to the representation used in Daly and Roose (2015), where the authors used the interface condition of Ding and Spelt (2007) which simplified equation (21) using an approximation to $\varphi$ near the air-water interface. Here we have chosen not to do this simplification as such an approximation is only strictly true at zero capillary pressure.

Once equations (20) and (21) have been solved it is possible to derive $\frac{\delta p}{\delta s}$ directly from the solution using

$$
S=\frac{\int_{\Omega} \varphi d V}{\|\Omega\|} .
$$

The second cell problem comes from a linearization of Stoke's equations to capture the effect of small pressure gradients across the soil volume, see Daly and Roose (2015) for details. The water velocity is then calculated for a known capillary pressure drop by solving

$$
\begin{array}{ccc}
\boldsymbol{\kappa}_{\boldsymbol{k}}^{\boldsymbol{\mu}} \cdot \boldsymbol{\nabla} \varphi=\nabla^{2} \chi_{k}^{\mu}, & \mathbf{x} \in \Omega, \quad(24) \\
\boldsymbol{\nabla} \cdot \bar{\eta}(\varphi)\left[\left(\boldsymbol{\nabla} \boldsymbol{\kappa}_{\boldsymbol{k}}^{\boldsymbol{\mu}}\right)+\left(\boldsymbol{\nabla} \boldsymbol{\kappa}_{\boldsymbol{k}}^{\boldsymbol{\mu}}\right)^{T}\right]-\nabla \omega_{k}^{\mu}=\varphi\left(\boldsymbol{\nabla} \chi_{k}^{\mu}+\hat{\boldsymbol{e}}_{\boldsymbol{k}}\right), & \mathbf{x} \in \Omega, \quad(25) \\
\boldsymbol{\nabla} \cdot \boldsymbol{\kappa}_{\boldsymbol{k}}^{\boldsymbol{\mu}}=0, & \mathbf{x} \in \Omega, \quad(26)
\end{array}
$$

with

$$
\begin{array}{cc}
\boldsymbol{\kappa}_{\boldsymbol{k}}^{\boldsymbol{\mu}}=0, & \mathbf{x} \in \Gamma, \\
\widehat{\boldsymbol{n}} \cdot \boldsymbol{\nabla} \chi_{k}^{\mu}=0, & \mathbf{x} \in \Gamma,
\end{array}
$$$$
\mathbf{x} \in \Gamma, \quad(27)
$$

on the soil geometry rescaled to have sides of unit length. Here $\boldsymbol{\kappa}_{\boldsymbol{k}}^{\boldsymbol{\mu}}$ is the dimensionless ratio between the local velocity and a unit capillary pressure drop, $\chi_{k}^{\mu}$ is the local variation in capillary pressure, $\omega_{k}^{\mu}$ is the local pressure variation and $\bar{\eta}(\varphi)$ is the normalized phase dependent viscosity. Hence, by linearity, the coefficient $K(S)$ is calculated using 
669

670

671

672

673

674

675

676

677

678

679

680

681

682

683

684

685

686

687

688

689

690

691

692

693

694

695

696

697

698

699

700

701

702

703

704

705

706

707

708

709

710

711

712

$$
K(S)=L_{y}^{2} \int_{\Omega} \varphi \boldsymbol{\kappa}_{k}^{\mu} \otimes \hat{\boldsymbol{e}}_{\boldsymbol{k}} d V .
$$

This method has been demonstrated for an idealized geometry (Daly and Roose 2015) and, more recently, has been used to evaluate the partially saturated hydraulic properties of a sieved sandy loam soil (Cooper et al. 2017). Equations (19) to (29) provide the means to calculate the WRC and partially saturated hydraulic conductivity based on knowledge of several important physical parameters: the soil geometry $(\Omega$ and $\Gamma)$, the air-water contact angle $(\theta)$, the viscosity $(\eta)$ and the surface tension $(\gamma)$. As discussed above, there is sufficient evidence to suggest that each of these parameters is altered in the rhizosphere relative to bulk soil.

The effect of surface tension on the movement of water in the rhizosphere is instantly apparent through equations (19) and (22). We observe that the variations in saturation will equilibrate on a timescale proportional to $\gamma$. In other words, increasing the surface tension will increase the rate at which water moves.

The effect of viscosity on the WRC is much more complex than that of surface tension. This is due to a number of factors. Firstly, the viscosity appears in Richards' equation both in terms of absolute value in the final equations (19) and and in terms of the viscosity ratio $\bar{\eta}(\varphi)$ in the cell problem used to calculate $K(S)$, equations (24) - (28). The appearance of $\bar{\eta}(\varphi)$ merits some discussion. Physically, $\bar{\eta}(\varphi)$ appears in the cell problem because the air phase will induce a small drag on the water phase proportional to the ratio $\eta^{a} / \eta^{w}$, where $\eta^{a}$ is the viscosity of air and $\eta^{w}$ is the viscosity of water. However, as $\eta^{w} \gg \eta^{a}$ this effect will be negligible. Hence, from a physical point of view we can simply consider the change in saturation as inversely proportional to viscosity, i.e., a larger viscosity causes the fluid to move much more slowly. From a mathematical perspective it is not obvious how to simplify equations (24) - (28) to take advantage of this observation, and the equations are typically solved with a numerically inconvenient region of very low viscosity relative to the water phase (Cooper et al. 2017; Daly and Roose 2015).

Secondly, the variation in viscosity associated with high mucilage concentrations is quite large. At some point the assumptions used to derive Richards' equation via homogenization, i.e., that capillary forces are dominant (Daly and Roose 2015), will break down. Carminati et al. (2017) found that, at a certain mucilage concentration, the air-water interface location is dominated by viscosity rather than capillary forces and liquid bridges form within the rhizosphere, which can increase the water holding capacity and, hence, increase water uptake in drier soils. It is not clear how this phenomenon could be integrated into equation (19). However, integrating these concepts into the homogenization framework could result in a fundamentally different set of equations to describe water dynamics in the rhizosphere. 


\subsection{The soil geometry}

In order to illustrate how the above equations can be used to predict water dynamics in the rhizosphere we have applied them to a set of soil geometries obtained using X-CT. The soils were imaged, segmented and turned into computational geometries on which we could calculate the soil parameters defined in Richards' equation (19).

Briefly, image analysis and simulations were carried out on two sets of X-CT images of a sand-textured Eutric Cambisol collected from Abergwyngregyn, North Wales. The soil was packed into $1 \mathrm{~mL}$ syringe barrels using contrasting packing routines resulting in an uncompacted and a compacted soil texture (volumetric water content approx. 25\%). For illustrative purpose, we consider the compact soil to be rhizosphere soil and the uncompacted soil to be bulk soil. Tomographic data were acquired at the TOMCAT beamline of the Swiss Light Source (Villigen, Switzerland), using a $19 \mathrm{kV}$ monochromatic beam. A singledistance phase retrieval algorithm proposed by Paganin et al. (2002) was applied to all projections, which were then reconstructed to 16-bit volumes. The resulting voxel side length was $1.6 \mu \mathrm{m}$. Image analysis was carried out on a representative cubic region of interest $\left(400 \mathrm{vx}^{3}\right)$ extracted from the original images.

The images were converted to 8-bit greyscale and histogram equalization was applied to increase contrast. Subsequently a 3D median filter $(\sigma=3)$ was applied to reduce small-scale noise. The resulting images had multimodal grey value histograms (Figure 3). Based on the histograms, four different phases were identified for segmentation. These are (in order of increasing grey value): 1) airfilled pores, 2) water filled pores, 3) a mixed phase of solid particles and water filled pores below resolution, 4) solid grains.

In addition to understanding how soil properties varied in the rhizosphere we also want to highlight the sensitivity of these calculations to image segmentation. Hence, two different segmentation approaches were used to classify the soil into the contrasting materials. First, a global thresholding approach using a multilevel adaptation of Otsu's method (Otsu 1979) was implemented in Matlab. Three thresholds were computed: $\mathrm{T}_{1}$ separating air-filled pores and water-filled pores, $\mathrm{T}_{2}$ separating water-filled pores and the mixed phase, and $\mathrm{T}_{3}$ separating the mixed phase and solid grains. The computed thresholds are shown in Figure 3 and Figure 4. As an alternative segmentation method, the trainable WEKA segmentation plugin in ImageJ was applied (Arganda-Carreras et al. 2017). This combines machine-learning algorithms with selected filters to produce a classifier for pixel-based segmentation, which is trained on manually chosen traces within the images. A single classifier was produced for both images using the "Laplacian", "Entropy" and "Neighbors" features with kernel sizes of $\sigma=1$ to 16 voxels and with traces for the individual phases drawn from 40 random slices within the image volumes. Finally the images from both the Otsu and the WEKA methods were post-processed using an isotropic 3D majority filter $(\sigma=5)$, which assigns each voxel to the modal class within the kernel. 
761

762

763

764

765

766

767

768

769

770

771

772

773

774

775

776

777

778

779

780

781

782

783

784

785

786

787

788

789

790

791

792

793

794

795

796

797

798

799

800

801

802

803

804

805

806

807

808

For simulation of the WRC, the images were simplified to binary images, using the threshold $\mathrm{T}_{3}$ to separate solid particles from the background. The WRC is calculated by solving equations (20) and (21) for a range of different capillary pressures and a set of different contact angles; $0^{\circ}, 10^{\circ}$ and $20^{\circ}$. We note that the image based method we are using is only capable of calculating water content in pores which can be resolved using X-CT. Hence, at the resolution of $1.6 \mu \mathrm{m}$ used in this study we would expect to only be able to resolve the WRC to a capillary pressure of approximately $-20 \mathrm{kPa}$ based on the assumption that pores of diameter lower than 10 voxels cannot be accurately determined. Following this line of reasoning, the current state of the art for synchrotron X-CT has been demonstrated down to resolutions approaching $100 \mathrm{~nm}$ (Stampanoni et al. 2010). Hence, in terms of resolution, we could expect to only be able to resolve the WRC to a capillary pressure of $\approx-300 \mathrm{kPa}$. However, in reality the field of view at this resolution is likely to be too low to capture enough of the large scale detail of the soil structure. The solution to equations (20) and (21) provides a geometric picture of where the air and water is held within the soil at fixed capillary pressure, Figure 5. By running simulations at a range of capillary pressure values the WRC can be inferred using equation (23).

The WRC and saturation dependent permeability were calculated for the bulk and rhizosphere soils for the three different contact angles using Comsol Multiphysics, a commercial finite element modelling package. Calculating the phase position for each capillary pressure required 20 GB RAM and between 15 minutes to 24 hours to run on the Iridis 4 super computer at the University of Southampton (batch nodes $64 \mathrm{~GB}$ RAM, 16 processors). The saturation dependent permeability calculations each required 390 GB RAM and 8 hours for the bulk soil sample, run on a bespoke desktop (48 processors, 640 GB RAM) and 300 GB RAM and 6 hours for the rhizosphere soil sample, also run on a bespoke desktop (24 processors, 512 GB RAM). This resulted in a total computation time of approximately 30 days.

\subsection{Results and discussion}

Both segmentation methods produced very similar results in the rhizosphere soil, while in the bulk soil, the Otsu method resulted in significantly smaller airfilled pore volume (Table 2). It is likely that this was caused by a biased histogram, which is known to be a cause for failure in finding a robust threshold (Schlüter et al. 2014). The threshold $\mathrm{T}_{1}$ in Figure 3 is clearly not placed between the two peaks, showing that the method did not perform well in this case. In Figure 4, it can be seen that the air-filled pore space is darker near the edges of the pores, which is an artefact, caused by the phase shift between two materials. The WEKA segmentation was better suited to avoid misclassification due to this artefact. Streaking artefacts caused some misclassification, as is evidenced in Figure 4i. The highlighted circles in Figure 4b, Figure 4e and Figure 4h show that the classification of smaller solid particles was more robust using Otsu's method.

The air and water distribution within the soil is shown as a function of the contact angle in Figure 5. Increasing the surface tension would have the effect of increasing the capillary pressure, see equation (22). We see that both the soil compaction and the contact angle used have a significant effect on the location of 
the air-water meniscus. This observation is confirmed by the WRC (Figure 6 a and $\mathrm{b}$ ) which shows that, for a capillary pressure of $3.8 \mathrm{kPa}$, changing the contact angle from $0^{\circ}$ to $20^{\circ}$ can create a change in saturation from $20 \%$ to $47 \%$ for the rhizosphere soil and $35 \%$ to $48 \%$ for the bulk soil. The permeability (Figure 6c and d) is also seen to vary between samples and as a function of contact angle. The bulk soil has a higher permeability than the rhizosphere soil and, in both cases, increasing the contact angle has the effect of decreasing the total wetted volume and decreasing the permeability.

To assess the effect of segmentation on the pore volume fraction and the WRC, $\mathrm{T}_{3}$ was perturbed by $+/-13$ (5\% of 256 possible grey values) resulting in an upper (Otsu upper) and lower (Otsu lower) threshold. In the rhizosphere soil sample the perturbation of the thresholds resulted in a change of pore volume fraction by $3 \%$, while in the bulk soil sample the change was $9 \%$ (Table 3 ). The saturated permeability is given in Figure 6 and has a value of $1.637 \times 10^{-6} \mathrm{~m}^{2}$ for the bulk soil and $1.195 \times 10^{-6} \mathrm{~m}^{2}$ for the rhizosphere soil. The corresponding permeability value change was $40 \%$ for the rhizosphere samples and $92 \%$ for the bulk soil samples.

The rhizosphere soil used in this study was created through an increase in soil compaction. The compaction decreased the porosity of this sample from approximately 0.76 in the bulk soil to 0.71 in the rhizosphere soil. This change caused an increase in the water holding capacity of the soil, i.e., a more negative capillary pressure is required to drain the soil. This corresponded to a decrease in the saturated permeability.

These results highlight how small changes in the geometry and measured parameters can produce large changes in the upscaled parameters calculated using image based modelling. In addition, we see that the image based modelling method can only ever be used to calculate the WRC down to the resolution limit. In other words, it is not possible to determine the spatial distribution of water in sub-resolution pores. These observations raise significant challenges in terms of imaging, measurements and modelling if these models are ever going to be truly predictive in describing water dynamics in the rhizosphere.

\section{Conclusions}

Soil water dynamics is complex and our ability to predict water dynamics on the plant scale depends on our ability to accurately observe and measure what happens at the pore scale. Image based modelling provides a tool which enables pore scale measurements and observations to be upscaled in order to provide information on the plant scale.

In the rhizosphere, soil water dynamics become even more complicated as the physical properties of soil can vary significantly from bulk soil. In this review we focused on the effects of geometrical measurements and contact angle and how these measurements carry through to the plant scale. Using an illustrative example, we observed that segmentation has little effect on parameters such as porosity. However, a small change in segmentation can induce a large change 
$(>90 \%)$ in the upscaled water parameters such as the saturated permeability. Secondly we observed how small changes in the air-water contact angle can create large changes in the water release curve. This observation is not surprising, but serves to illustrate the need for careful small scale measurement of this parameter.

The observations presented in this review highlight several key challenges in understanding and predicting the behavior of water in the rhizosphere. Firstly, the effects of viscosity, contact angle, surface tension and geometry variation local to roots needs to be included in any complete mathematical description of the rhizosphere. Homogenization and image based modelling provide one route to achieve this from fundamental physical observations. Secondly, precise measurements of rhizosphere properties need to be made and incorporated into these models. High resolution X-CT provides one route through which this could be achieved. However, in order to achieve the resolution necessary to parameterize the WRC in very dry soils we would have to compromise on field of view. Hence, an additional layer of averaging may be needed at this scale to move between the nanometer scale and the micro-scale resolved in this study. Thirdly, advances in computational tools are needed in order to enable optimization of properties and enable the possibility of 'designer rhizospheres', where the pore scale geometrical and structural properties of soils could be explicitly tailored to provide ideal conditions for the growth of specific plants. Finally, these models require validation, which is difficult to achieve on the rhizosphere scale due to the timescales associated with mucilage dynamics and the small length scales involved (Carminati et al. 2016).

We have highlighted key challenges which, in the authors' opinion, would benefit from further research both experimentally and mathematically. Despite the challenges, the subject of water dynamics in the rhizosphere has received significant attention. Thanks to the recent improvements in images, quantification and modelling our understanding of how rhizosphere plant soil interactions affect water movement continues to improve.

\section{Acknowledgements}

KRD, SDK, AvV and TR are funded by ERC Consolidator grant 646809 (Data Intensive Modelling of the Rhizosphere Processes). NK and LC are funded by BBSRC grant BB/L026058/1 (Rhizosphere by design: breeding to select root traits that physically manipulate soil). SDK is also supported by a University of Southampton New Frontiers Fellowship. JE is funded by the University of Nevada Reno Vice President of Research and Innovation. The authors acknowledge the use of the IRIDIS High Performance Computing Facility, and associated support services at the University of Southampton, in the completion of this work. The authors acknowledge the use of beam-time at the TOMCAT beamline of the Swiss Light Source (Paul Scherrer Institute, Villigen, Switzerland), and the assistance of Dr Goran Lovric in acquiring SRXCT data. Finally, the authors also acknowledge members of the 'Rooty Team' at University of Southampton for helpful discussions related to this work and the anonymous reviewers whose input has greatly improved this paper. 
904

905

906

907

908

909

910

911

912

913

914

915

916

917

918

919

920

921

922

923

924

925

926

927

928

929

930

931

932

933

934

935

936

937

938

939

940

941

942

943

944

945

946

947

948

\section{References}

Abramowitz M, Stegun IA (1964) Handbook of mathematical functions: with formulas, graphs, and mathematical tables. Courier Corporation.

Ahmed MA, Zarebanadkouki M, Kaestner A, Carminati A (2016) Measurements of water uptake of maize roots: the key function of lateral roots. Plant and soil 398: 59-77.

Anderson D, McFadden GB, Wheeler A (1998) Diffuse-interface methods in fluid mechanics. Annual review of fluid mechanics 30: 139-165.

Andrew M, Bijeljic B, Blunt MJ (2014) Pore-scale contact angle measurments at reservoir conditions using X-ray microtomography. Advances in Water Resources 68: 24-31.

Aravena JE, Berli M, Ghezzehei TA, Tyler SW (2010) Effects of root-induced compaction on rhizosphere hydraulic properties-x-ray microtomography imaging and numerical simulations. Environ Sci Technol 45: 425-431.

Aravena JE, Berli M, Menon M, Ghezzehei TA, Mandava AK, Regentova EE, Pillai NS, Steude J, Young MH, Nico PS (2013) Synchrotron X-ray microtomography-new means to quantify root induced changes of rhizosphere physical properties. Soil-water-root processes: advances in tomography and imaging: 39-67.

Aravena JE, Berli M, Ruiz S, Suárez F, Ghezzehei TA, Tyler SW (2014) Quantifying coupled deformation and water flow in the rhizosphere using X-ray microtomography and numerical simulations. Plant and soil 376: 95-110.

Arganda-Carreras I, Kaynig V, Rueden C, Eliceiri KW, Schindelin J, Cardona A, Sebastian Seung H (2017) Trainable Weka Segmentation: a machine learning tool for microscopy pixel classification. Bioinformatics: btx180.

Baetz U, Martinoia E (2014) Root exudates: the hidden part of plant defense. Trends in Plant Science 19: 90-98. doi: https://doi.org/10.1016/j.tplants.2013.11.006.

Bear J (2013) Dynamics of fluids in porous media. Courier Corporation.

Berg S, Ott H, Klapp SA, Schwing A, Neiteler R, Brussee N, Makurat A, Leu L, Enzmann F, Schwarz J-O (2013) Real-time 3D imaging of Haines jumps in porous media flow. Proceedings of the National Academy of Sciences 110: 3755-3759.

Berkelhammer M, Noone D, Wong T, Burns S, Knowles J, Kaushik A, Blanken P, Williams M (2016) Convergent approaches to determine an ecosystem's transpiration fraction. Global Biogeochemical Cycles 30: 933-951.

Bittelli M (2011) Measuring soil water content: A review. HortTechnology 21: 293-300.

Blunt MJ (2001) Flow in porous media - pore-network models and multiphase flow. Current Opinion in Colloid \& Interface Science 6: 197-207. doi: Doi 10.1016/S1359-0294(01)00084-X.

Blunt MJ, Bijeljic B, Dong H, Gharbi O, Iglauer S, Mostaghimi P, Paluszny A, Pentland C (2013) Pore-scale imaging and modelling. Advances in Water Resources 51: 197-216. doi: Doi 10.1016/J.Advwatres.2012.03.003.

Brooks R, Corey T (1964) Hydraulic properties of porous media. 
Brutsaert W (1982) Evaporation into the Atmosphere. Theory, History, and Applications; Dordrecht: Holland, D. Reidel Co.

Buckton G, Darcy P, McCarthy D (1995) The extent of errors associated with contact angles 3 . The influence of surface roughness effects on angles measured using a Wilhelmy plate technique for powders. Colloids and Surfaces A: Physicochemical and Engineering Aspects 95: 27-35.

Burridge R, Keller JB (1981) Poroelasticity equations derived from microstructure. The Journal of the Acoustical Society of America 70: 1140-1146.

Capitani MI, Ixtaina VY, Nolasco SM, Tomás MC (2013) Microstructure, chemical composition and mucilage exudation of chia (Salvia hispanica L.) nutlets from Argentina. Journal of the Science of Food and Agriculture 93: 38563862. doi: $10.1002 /$ jsfa.6327.

Carminati A (2012) A model of root water uptake coupled with rhizosphere dynamics. Vadose Zone Journal 11.

Carminati A, Benard P, Ahmed M, Zarebanadkouki M (2017) Liquid bridges at the root-soil interface. Plant and Soil: 1-15.

Carminati A, Moradi A, Vetterlein D, Vontobel P, Lehmann E, Weller U, Vogel H-J, Oswald S (2010) Dynamics of soil water content in the rhizosphere. Plant and Soil 332: 163-176. doi: 10.1007/s11104-010-0283-8.

Carminati A, Vetterlein D, Weller U, Vogel H-J, Oswald SE (2009) When roots lose contact. Vadose Zone Journal 8: 805-809.

Carminati A, Zarebanadkouki M, Kroener E, Ahmed M, Holz M (2016) Biophysical rhizosphere processes affecting root water uptake. Annals of Botany: mcw113.

Cioranescu D, Donato P (1999) An introduction to homogenization. Oxford University Press Oxford.

Cnudde V, Boone M (2013) High-resolution X-ray computed tomography in geosciences: A review of the current technology and applications. EarthScience Reviews 123: 1-17.

Cooper LJ, Daly KR, Naveed M, Koebernick N, Hallett P, Bengough AG, George TS, Sinclair I, Roose T (2017) Fluid flow in porous media using image based modelling to parametrise Richards' equation. Proc Roy Soc A (Under revisions).

Czachor H, Hallett PD, Lichner L, Jozefaciuk G (2013) Pore shape and organic compounds drive major changes in the hydrological characteristics of agricultural soils. European Journal of Soil Science 64: 334-344.

Czarnes S, Hallett PD, Bengough AG, Young IM (2000) Root- and microbialderived mucilages affect soil structure and water transport. European Journal of Soil Science 51: 435-443.

Dal Ferro N, Strozzi A, Duwig C, Delmas P, Charrier P, Morari F (2015) Application of smoothed particle hydrodynamics (SPH) and pore morphologic model to predict saturated water conductivity from X-ray CT imaging in a silty loam Cambisol. Geoderma 255: 27-34.

Daly KR, Keyes SD, Masum S, Roose T (2016) Image-based modelling of nutrient movement in and around the rhizosphere. Journal of experimental botany 67: 1059-1070.

Daly KR, Mooney S, Bennett M, Crout N, Roose T, Tracy S (2015) Assessing the influence of the rhizosphere on soil hydraulic properties using X-ray 
Computed Tomography and numerical modelling. Journal of Experimental Botany 66: 2305-2314.

Daly KR, Roose T (2014) Multiscale modelling of hydraulic conductivity in vuggy porous media. Proceedings Mathematical, physical, and engineering sciences 470: 20130383. doi: 10.1098/rspa.2014.0564.

Daly KR, Roose T (2015) Homogenization of two fluid flow in porous media. Proceedings Mathematical, physical, and engineering sciences 471: 20140564. doi: 10.1098/rspa.2014.0564.

Daly KR, Tracy SR, Crout NM, Mairhofer S, Pridmore TP, Mooney SJ, Roose T (2017) Quantification of root water uptake in soil using X - ray Computed Tomography and image based modelling. Plant, cell \& environment.

Dawson TE, Ehleringer JR (1991) Streamside trees that do not use stream water. Nature 350: 335-337.

De Jeu R, Wagner W, Holmes T, Dolman A, Van De Giesen N, Friesen J (2008) Global soil moisture patterns observed by space borne microwave radiometers and scatterometers. Surveys in Geophysics 29: 399-420.

Dean T, Bell J, Baty A (1987) Soil moisture measurement by an improved capacitance technique, Part I. Sensor design and performance. Journal of Hydrology 93: 67-78.

Dexter A (1987) Compression of soil around roots. Plant and Soil 97: 401-406.

Dhiman I, Bilheux H, DeCarlo K, Painter SL, Santodonato L, Warren JM (2017) Quantifying root water extraction after drought recovery using sub-mm in situ empirical data. Plant and Soil: 1-17.

Ding H, Spelt PD (2007) Wetting condition in diffuse interface simulations of contact line motion. Physical Review E 75: 046708.

Doussan C, Pierret A, Garrigues E, Pagès L (2006) Water uptake by plant roots: II-modelling of water transfer in the soil root-system with explicit account of flow within the root system-comparison with experiments. Plant and soil 283: 99-117.

Downie HF, Adu MO, Schmidt S, Otten W, Dupuy LX, White PJ, Valentine TA (2014) Challenges and opportunities for quantifying roots and rhizosphere interactions through imaging and image analysis. Plant, cell \& environment. doi: 10.1111/pce.12448.

Dunbabin VM, Postma JA, Schnepf A, Pagès L, Javaux M, Wu L, Leitner D, Chen YL, Rengel Z, Diggle AJ (2013) Modelling root-soil interactions using threedimensional models of root growth, architecture and function. Plant and soil 372: 93-124.

Durner W, Or D (2005) Soil water potential measurement. Encyclopedia of hydrological sciences.

Edmond Ghanem M, Han R-M, Classen B, Quetin-Leclerq J, Mahy G, Ruan C-J, Qin P, Pérez-Alfocea F, Lutts S (2010) Mucilage and polysaccharides in the halophyte plant species Kosteletzkya virginica: Localization and composition in relation to salt stress. Journal of Plant Physiology 167: 382-392. doi: https://doi.org/10.1016/j.jplph.2009.10.012.

Ehleringer J, Dawson T (1992) Water uptake by plants: perspectives from stable isotope composition. Plant, cell \& environment 15: 1073-1082.

Esser HG, Carminati A, Vontobel P, Lehmann EH, Oswald SE (2010) Neutron radiography and tomography of water distribution in the root zone. Journal of Plant Nutrition and Soil Science 173: 757-764. 
Evaristo J, Jasechko S, McDonnell JJ (2015) Global separation of plant transpiration from groundwater and streamflow. Nature 525: 91.

Evaristo J, McDonnell JJ (2017) Prevalence and magnitude of groundwater use by vegetation: a global stable isotope meta-analysis. Scientific Reports 7.

Evaristo J, McDonnell JJ, Scholl MA, Bruijnzeel LA, Chun KP (2016) Insights into plant water uptake from xylem - water isotope measurements in two tropical catchments with contrasting moisture conditions. Hydrological Processes 30: 3210-3227.

Fatt I (1956) The network model of porous media.

Good SP, Noone D, Bowen G (2015) Hydrologic connectivity constrains partitioning of global terrestrial water fluxes. Science 349: 175-177.

Granier A (1985) A new method of sap flow measurement in tree stems. Ann For Sci 42: 193-200.

Grant CD, Dexter A (1989) Generation of microcracks in molded soils by rapid wetting. Soil Research 27: 169-182.

Gregory P (2006) Roots, rhizosphere and soil: the route to a better understanding of soil science? European Journal of Soil Science 57: 2-12.

Hartmann A, Rothballer M, Schmid M (2008) Lorenz Hiltner, a pioneer in rhizosphere microbial ecology and soil bacteriology research. Plant and Soil 312: 7-14.

Hillel D (1998) Environmental soil physics: Fundamentals, applications, and environmental considerations. Academic press.

Hiltner L (1904) Über neuere Erfahrungen und Probleme auf dem Gebiete der Bodenbakteriologie unter besonderer Berücksichtigung der Gründüngung und Brache. Arbeiten der Deutschen Landwirtschaftlichen Gesellschaft 98: 59-78.

Hollinger SE, Isard SA (1994) A soil moisture climatology of Illinois. Journal of Climate 7: 822-833.

Hopmans JW, Schoups G (2005) Soil water flow at different spatial scales. Encyclopedia of hydrological sciences.

Hornung U (1997) Homogenization and porous media. Springer.

Houston AN, Schmidt S, Tarquis A, Otten W, Baveye PC, Hapca SM (2013) Effect of scanning and image reconstruction settings in X-ray computed microtomography on quality and segmentation of 3D soil images. Geoderma 207: 154-165.

Kaestner A, Lehmann E, Stampanoni M (2008) Imaging and image processing in porous media research. Advances in Water Resources 31: 1174-1187.

Kang M, Perfect E, Cheng C, Bilheux H, Lee J, Horita J, Warren J (2014) Multiple pixel-scale soil water retention curves quantified by neutron radiography. Advances in Water Resources 65: 1-8.

Keller JB (1980) Darcy's law for flow in porous media and the two-space method. Nonlinear partial differential equations in engineering and applied science (Proc Conf, Univ Rhode Island, Kingston, RI, 1979). Dekker New York.

Keyes SD, Daly KR, Gostling NJ, Jones DL, Talboys P, Pinzer BR, Boardman R, Sinclair I, Marchant A, Roose T (2013) Rapid report High resolution synchrotron imaging of wheat root hairs growing in soil and image based modelling of phosphate uptake. New Phytologist 198: 1023-1029. 
Keyes SD, Zygalakis K, Roose T (2015) Explicit structural modelling of root-hair and soil interactions at the micron-scale parameterized by synchrotron $\mathrm{x}$ ray computed tomography. Submitted to Jounal of Experimental Botany 19/05/2015.

Knee EM, Gong F-C, Gao M, Teplitski M, Jones AR, Foxworthy A, Mort AJ, Bauer WD (2001) Root Mucilage from Pea and Its Utilization by Rhizosphere Bacteria as a Sole Carbon Source. Molecular Plant-Microbe Interactions 14: 775-784. doi: 10.1094/MPMI.2001.14.6.775.

Knight J, Raats P (2016) The contributions of Lewis Fry Richardson to drainage theory, soil physics, and the soil-plant-atmosphere continuum. EGU General Assembly Conference Abstracts.

Koebernick N, Daly KR, Keyes SD, George TS, Brown LK, Raffan A, Cooper LJ, Naveed M, Bengough AG, Sinclair I (2017) High - resolution synchrotron imaging shows that root hairs influence rhizosphere soil structure formation. New Phytologist.

Koebernick N, Huber K, Kerkhofs E, Vanderborght J, Javaux M, Vereecken H, Vetterlein D (2015) Unraveling the hydrodynamics of split root water uptake experiments using CT scanned root architectures and three dimensional flow simulations. Frontiers in plant science 6: 370.

Kool D, Agam N, Lazarovitch N, Heitman J, Sauer T, Ben-Gal A (2014) A review of approaches for evapotranspiration partitioning. Agricultural and forest meteorology 184: 56-70.

Kusumaatmaja H, Yeomans JM (2010) Lattice Boltzmann simulations of wetting and drop dynamics. Simulating Complex Systems by Cellular Automata. Springer.

Lee CK, Mei CC (1997) Re-examination of the equations of poroelasticity. International journal of engineering science 35: 329-352.

Lukyanov AV, Likhtman AE (2016) Dynamic Contact Angle at the Nanoscale: A Unified View. ACS Nano 10: 6045-6053.

Manahiloh KN, Meehan CL (2017) Determining the Soil Water Characterisitc Curve and Interfacial Contact Angle from Microstructural Analysis of XRay CT Images. Journal of Geotechnical and Geoenvironmental Engineering 143: 04017034.

Masum S, Kirk GJ, Daly K, Roose T (2016) The effect of non - uniform microscale distribution of sorption sites on solute diffusion in soil. European Journal of Soil Science 67: 514-522.

Menon M, Robinson B, Oswald SE, Kaestner A, Abbaspour KC, Lehmann E, Schulin R (2007) Visualization of root growth in heterogeneously contaminated soil using neutron radiography. European Journal of Soil Science 58: 802-810.

Mohammed IU, Deeni Y, Hapca SM, McLaughlin K, Spiers AJ (2014) Predicting the minimum liquid surface tension activity of pseudomonads expressing biosurfactants. Letters in Applied Microbiology 60: 37-43.

Mooney SJ, Pridmore TP, Helliwell J, Bennett MJ (2012) Developing X-ray Computed Tomography to non-invasively image 3-D root systems architecture in soil. Plant and Soil 352: 1-22. doi: Doi 10.1007/S11104011-1039-9.

Moradi AB, Carminati A, Vetterlein D, Vontobel P, Lehmann E, Weller U, Hopmans JW, Vogel HJ, Oswald SE (2011) Three - dimensional visualization and 
quantification of water content in the rhizosphere. New Phytologist 192: 653-663.

Morse SR (1990) Water balance in Hemizonia luzulifolia: the role of extracellular polysaccharides. Plant, Cell \& Environment 13: 39-48. doi: 10.1111/j.1365-3040.1990.tb01297.x.

Mualem Y (1974) A conceptual model of hysteresis. Water Resources Research 10: 514-520.

Mualem Y (1976a) Hysteretical models for prediction of the hydraulic conductivity of unsaturated porous media. Water resources research 12: 1248-1254.

Mualem Y (1976b) A new model for predicting the hydraulic conductivity of unsaturated porous media. Water resources research 12: 513-522.

Naveed M, Brown L, Raffan A, George T, Bengough A, Roose T, Sinclair I, Koebernick N, Cooper L, Hallett P (2017) Plant exudates can either stabilise or weaken soils depending on species, origin and time. European Journal of Soil Science.

Nestler J, Keyes SD, Wissuwa M (2016) Root hair formation in rice (Oryza sativa L.) differs between root types and is altered in artificial growth conditions. Journal of experimental botany 67: 3699-3708.

Ngom NF, Garnier P, Monga O, Peth S (2011) Extraction of three-dimensional soil pore space from microtomography images using a geometrical approach. Geoderma 163: 127-134.

Njoku EG, Jackson TJ, Lakshmi V, Chan TK, Nghiem SV (2003) Soil moisture retrieval from AMSR-E. IEEE transactions on Geoscience and remote sensing 41: 215-229.

Oburger E, Schmidt H (2016) New methods to unravel rhizosphere processes. Trends in plant science 21: 243-255.

Oswald SE, Menon M, Carminati A, Vontobel P, Lehmann E, Schulin R (2008) Quantitative imaging of infiltration, root growth, and root water uptake via neutron radiography. Vadose Zone Journal 7: 1035-1047.

Otsu N (1979) A threshold selection method from gray-level histograms. IEEE transactions on systems, man, and cybernetics 9: 62-66.

Paganin D, Mayo SC, Gureyev TE, Miller PR, Wilkins SW (2002) Simultaneous phase and amplitude extraction from a single defocused image of a homogeneous object. Journal of Microscopy 206: 33-40. doi: 10.1046/j.1365-2818.2002.01010.x.

Pavliotis G, Stuart A (2008) Multiscale methods: averaging and homogenization. Springer Science \& Business Media.

Peth S, Horn R, Beckmann F, Donath T, Fischer J, Smucker AJM (2008) Threedimensional quantification of intra-aggregate pore-space features using synchrotron-radiation-based microtomography. Soil Science Society of America Journal 72: 897-907.

Philip J (1980) Field heterogeneity: Some basic issues. Water Resources Research 16: 443-448.

Pot V, Peth S, Monga O, Vogel LE, Genty A, Garnier P, L.Vieuble-Gonod (2015) Three-dimensional distribution of water and air in soil pores: Comparison of two-phase two relaxation times lattice-Blotzmann and morphological model outputs with synchrotron X-ray computed tomography data. Advances in Water Resources 84: 87-102. 
Read DB, Gregory PJ (1997) Surface tension and viscosity of axenic maize and lupin root mucilages. New Phytology 137: 623-628.

Richards LA (1931) Capillary conduction of liquids through porous mediums. Journal of Applied Physics 1: 318-333.

Richardson LF (2007) Weather prediction by numerical process. Cambridge University Press.

Robinson D, Binley A, Crook N, Day - Lewis F, Ferré T, Grauch V, Knight R, Knoll M, Lakshmi V, Miller R (2008a) Advancing process - based watershed hydrological research using near - surface geophysics: A vision for, and review of, electrical and magnetic geophysical methods. Hydrological Processes 22: 3604-3635.

Robinson D, Campbell C, Hopmans J, Hornbuckle B, Jones SB, Knight R, Ogden F, Selker J, Wendroth O (2008b) Soil moisture measurement for ecological and hydrological watershed-scale observatories: A review. Vadose Zone Journal 7: 358-389.

Robock A, Vinnikov KY, Srinivasan G, Entin JK, Hollinger SE, Speranskaya NA, Liu S, Namkhai A (2000) The global soil moisture data bank. Bulletin of the American Meteorological Society 81: 1281-1299.

Roose T, Keyes S, Daly K, Carminati A, Otten W, Vetterlein D, Peth S (2016) Challenges in imaging and predictive modeling of rhizosphere processes. Plant and Soil: 1-30.

Roose T, Schnepf A (2008) Mathematical models of plant-soil interaction. Philosophical Transactions of the Royal Society A: Mathematical, Physical and Engineering Sciences 366: 4597-4611.

Schaap MG, Porter ML, Christensen BSB, Wildenschild D (2007) Comparison of pressure-saturation characteristics derived from computed tomography and lattice Boltmann simulations. Water Resources Research 43: W12S06.

Scheibe TD, Perkins WA, Richmond MC, McKinley MI, Romero - Gomez PD, Oostrom M, Wietsma TW, Serkowski JA, Zachara JM (2015) Pore - scale and multiscale numerical simulation of flow and transport in a laboratory - scale column. Water Resources Research 51: 1023-1035.

Schlüter S, Sheppard A, Brown K, Wildenschild D (2014) Image processing of multiphase images obtained via $\mathrm{X}$ - ray microtomography: A review. Water Resources Research 50: 3615-3639.

Schwartz N, Carminati A, Javaux M (2016) The impact of mucilage on root water uptake-A numerical study. Water Resources Research 52: 264-277.

Shanga J, Flury M, Harsh JB, Zollars RL (2008) Comparison of different methods to measure contact angles of soil colloids. Journal of Colloid and Interface Science 328: 299-307.

Smith KA (2000) Soil and environmental analysis: physical methods, revised, and expanded. CRC Press.

Stampanoni M, Mokso R, Marone F, Vila-Comamala J, Gorelick S, Trtik P, Jefimovs K, David C (2010) Phase-contrast tomography at the nanoscale using hard x rays. Physical Review B 81: 140105.

Tartar L (1980) Incompressible fluid flow in a porous medium-convergence of the homogenization process. Appendix of [16] T Muthukumar Department of Mathematics, Indian Institute of Science, Bangalore560012, India E-mail address: tmk@ math iisc ernet in. 
Thorburn PJ, Hatton TJ, Walker GR (1993) Combining measurements of transpiration and stable isotopes of water to determine groundwater discharge from forests. Journal of Hydrology 150: 563-587.

Topp GC, Reynolds WD (1998) Time domain reflectometry: A seminal technique for measuring mass and energy in soil. Soil and Tillage Research 47: 125132.

Tracy SR, Daly KR, Sturrock CJ, Crout NM, Mooney SJ, Roose T (2015) Three dimensional quantification of soil hydraulic properties using $\mathrm{X}$ - ray Computed Tomography and image - based modeling. Water Resources Research 51: 1006-1022.

Van Genuchten MT (1980) A closed-form equation for predicting the hydraulic conductivity of unsaturated soils. Soil science society of America journal 44: 892-898.

Vereecken H, Schnepf A, Hopmans J, Javaux M, Or D, Roose T, Vanderborght J, Young M, Amelung W, Aitkenhead M (2016) Modelling Soil Processes: Key challenges and new perspectives. Young 1001: 10.

Vereecken H, Weynants M, Javaux M, Pachepsky Y, Schaap M, Genuchten MT (2010) Using pedotransfer functions to estimate the van GenuchtenMualem soil hydraulic properties: a review. Vadose Zone Journal 9: 795820.

Vinnikov KY, Yeserkepova I (1991) Soil moisture: Empirical data and model results. Journal of climate 4: 66-79.

Wagner W, Blöschl G, Pampaloni P, Calvet J-C, Bizzarri B, Wigneron J-P, Kerr Y (2007) Operational readiness of microwave remote sensing of soil moisture for hydrologic applications. Hydrology Research 38: 1-20.

Walker TS, Bais HP, Grotewold E, Vivanco JM (2003) Root Exudation and Rhizosphere Biology. Plant Physiology 132: 44-51. doi: 10.1104/pp.102.019661.

Whalley WR, Riseley B, Leeds - Harrison PB, Bird NR, Leech PK, Adderley WP (2005) Structural differences between bulk and rhizosphere soil. European Journal of Soil Science 56: 353-360.

Wigneron J-P, Calvet J-C, Pellarin T, Van de Griend A, Berger M, Ferrazzoli P (2003) Retrieving near-surface soil moisture from microwave radiometric observations: current status and future plans. Remote Sensing of Environment 85: 489-506.

Yang X, Dong M, Huang Z (2010) Role of mucilage in the germination of Artemisia sphaerocephala (Asteraceae) achenes exposed to osmotic stress and salinity. Plant Physiology and Biochemistry 48: 131-135. doi: https://doi.org/10.1016/j.plaphy.2009.12.006.

Yegorenkova IV, Tregubova KV, Ignatov VV (2013) Paenibacillus polymyxa Rhizobacteria and Their Synthesized Exoglycans in Interaction with Wheat Roots: Colonization and Root Hair Deformation. Current Microbiology 66: 481-486.

Young IM (1995) Variation in moisture contents between bulk soil and the rhizosheath of wheat (Triticum-aestivum L cv Wembley). . New Phytologist 130: 135-139.

Yu X, Fu Y, Lu S (2017) Characterization of the pore structure and cementing substances of soil aggregates by a combination of synchrotron radiation 

$\mathrm{X}$ - ray micro - computed tomography and scanning electron microscopy. European Journal of Soil Science 68: 66-79. root-soil interface of lupin in sandy soil after drying and rewetting. Plant and soil 398: 267-280.

Zarebanadkouki M, Kim YX, Moradi AB, Vogel H-J, Kaestner A, Carminati A (2012) Quantification and modeling of local root water uptake using neutron radiography and deuterated water. Vadose Zone Journal 11.

Zhang C, Liu Z, Deng P (2016a) Contact angle of soil minerals: A molecular dynamics study. Computers and Geotechnics 75: 48-56.

Zhang ZQ, Si BC, Li Z, Evaristo J, McDonnell JJ (2016b) Tritium analysis shows apple trees may be transpiring water several decades old. Hydrological Processes.

Zygalakis K, Kirk G, Jones D, Wissuwa M, Roose T (2011) A dual porosity model of nutrient uptake by root hairs. New Phytologist 192: 676-688.

Zygalakis K, Roose T (2012) A mathematical model for investigating the effect of cluster roots on plant nutrient uptake. The European Physical JournalSpecial Topics 204: 103-118. 
1308 Figures

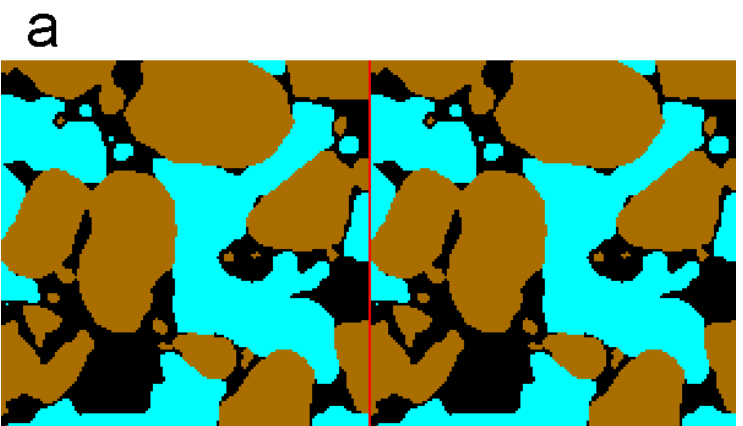

b

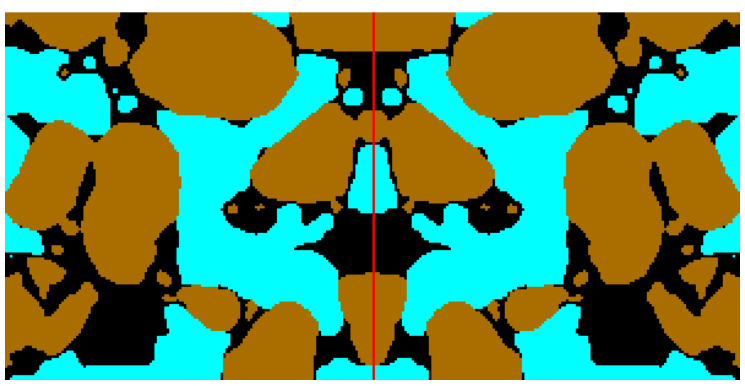

1309

1310 Figure 1: Periodicity of soils enforced by (a) translation, showing a jump discontinuity in the soil 1311 structure, and (b) reflection.

1312 


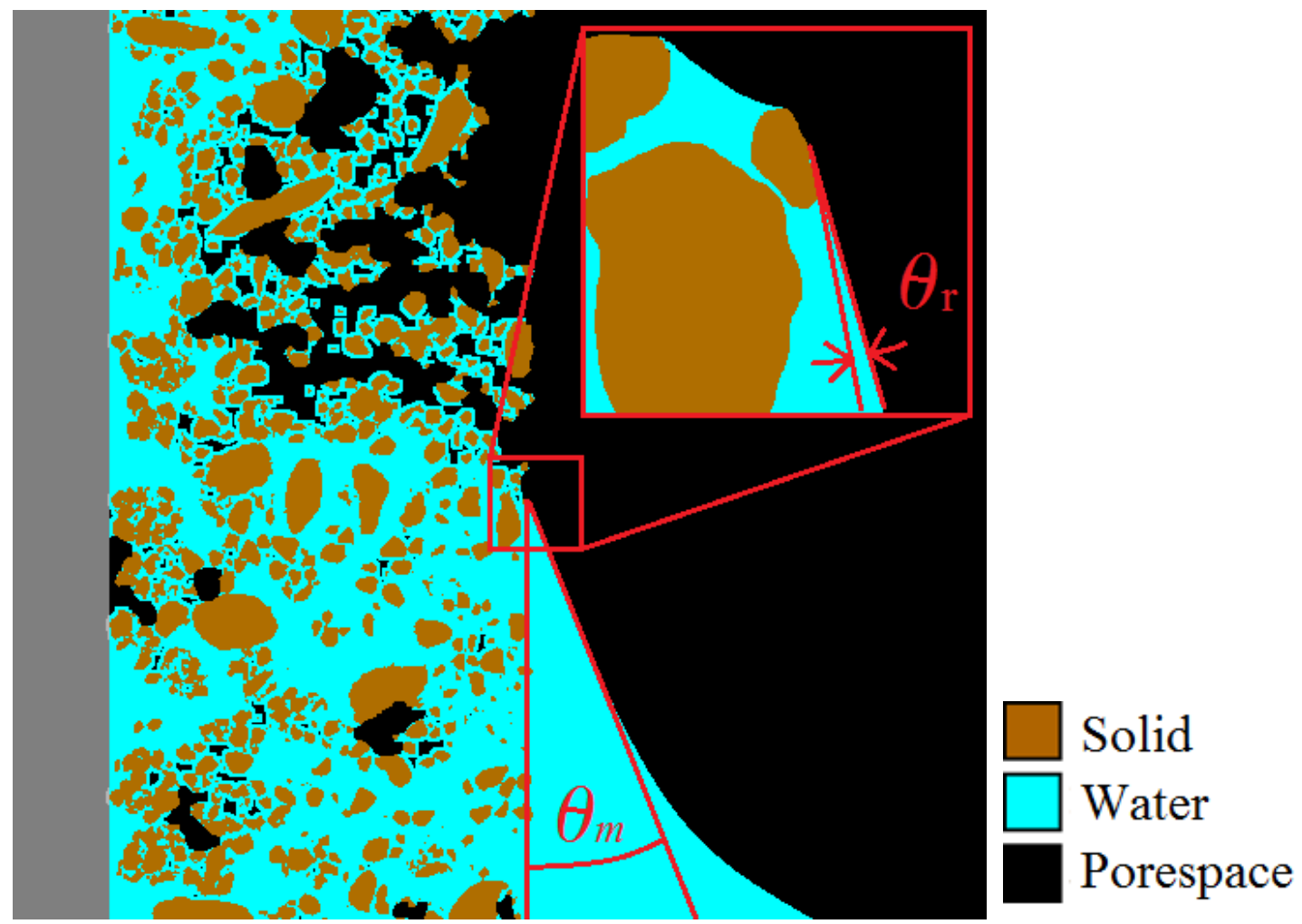

1315 Figure 2 Schematic showing macroscopic contact angle $\theta_{m}$ measured relative to the vertical and the 1316 microscopic or real contact angle $\theta_{r}$ measured relative to the soil particle. 

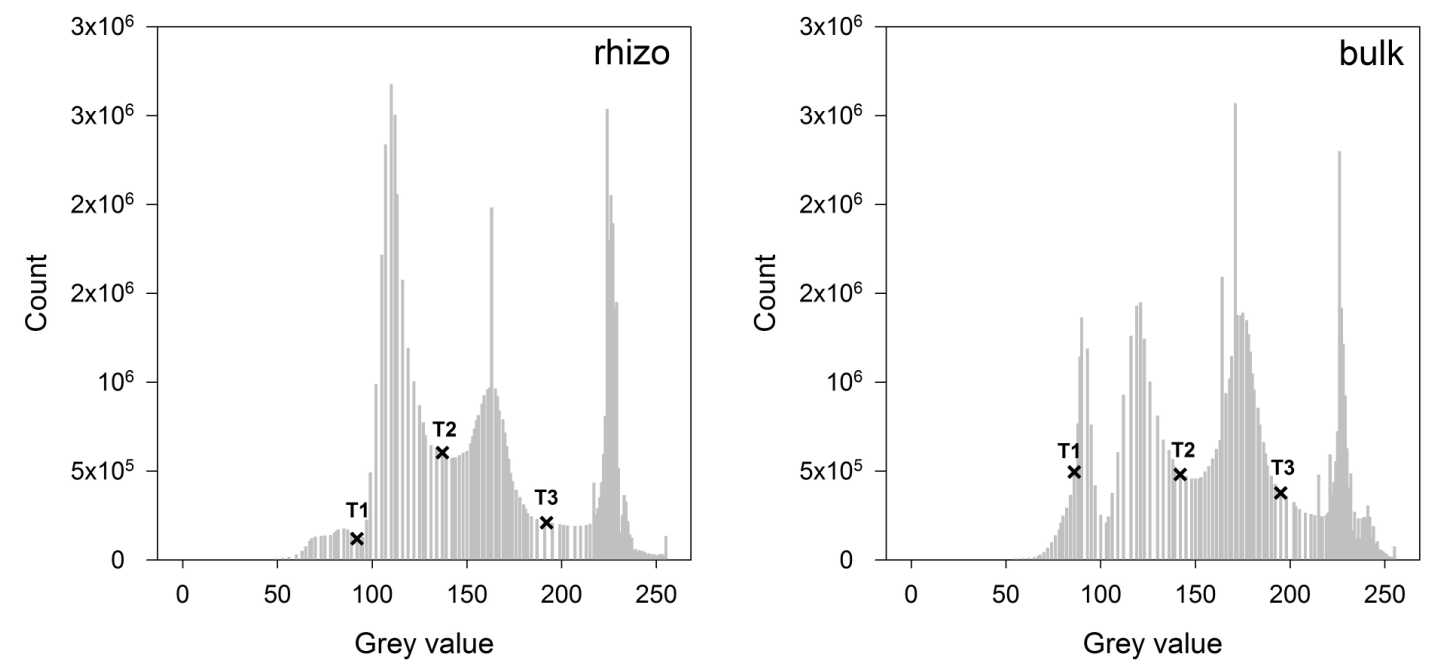

Figure 3: Grey value histograms of the CT images of bulk and rhizosphere soil after conversion to 8bit and histogram equalisation. Thresholds for classification of the soil computed with Otsu's method are shown as diagonal crosses. $\mathrm{T} 1$ is the threshold between air-filled and water-filled pores. T2 is the threshold between water filled pores and clay-water mixed phase, T3 is the threshold between clay-water mixed phase and solid particles. 

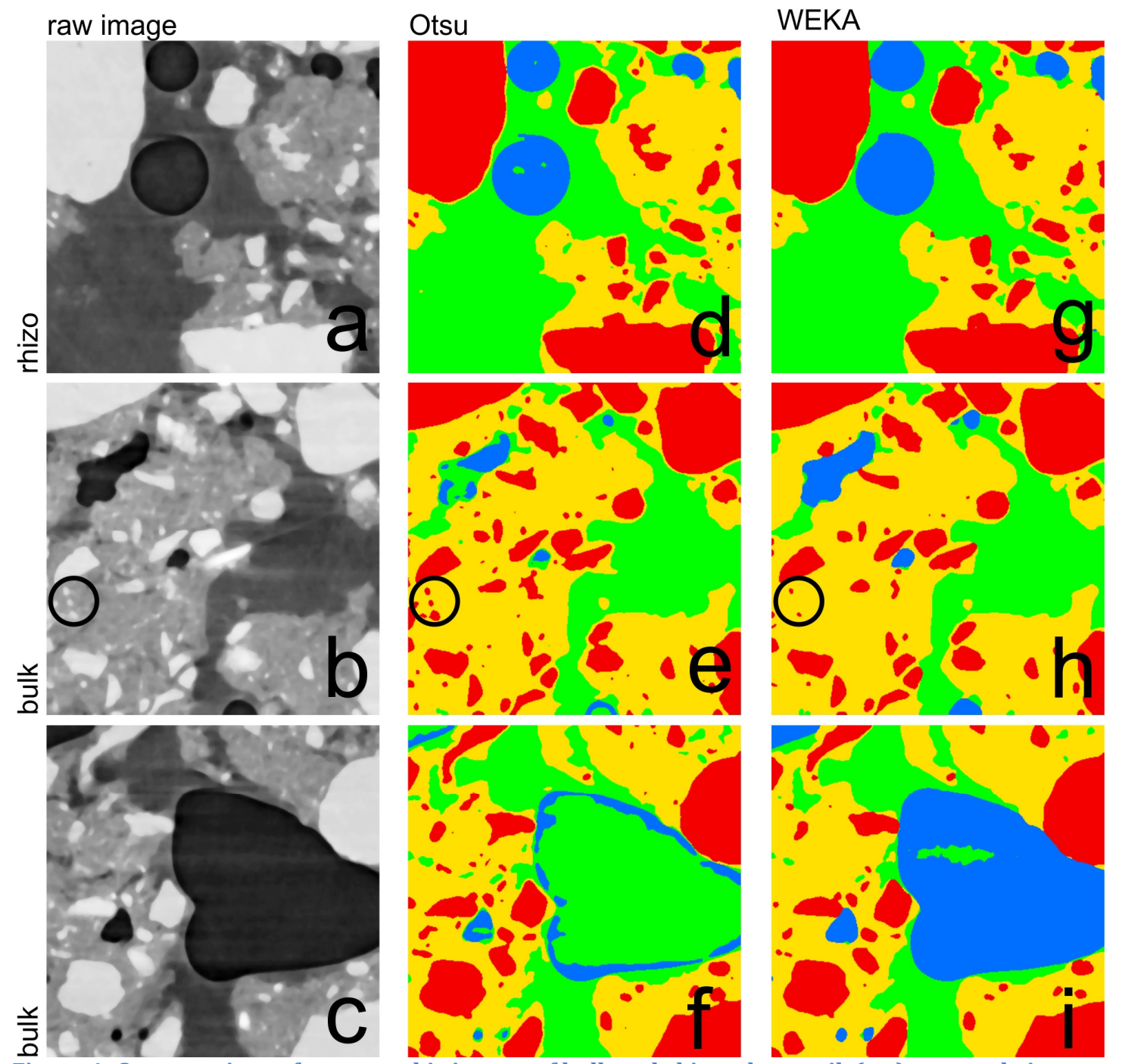

Figure 4: Cross-sections of tomographic images of bulk and rhizosphere soil. (a-c) grey scale images 1330 (we note that figures $b$ and $c$ are two distinct regions of the same bulk sample), (d-i) Results of multiphase classification using Otsu's method (d-f), and trainable WEKA segmentation (g-i), respectively. Blue is air-filled pore space, green is water filled pore space, yellow is clay-water mixed phase, red are solid mineral grains. The circles in (b), (e) and (h) show that the classification of smaller solid particles was more robust using Otsu's method. The rhizosphere soil had less pore space, lower permeability and a steeper WRC. 


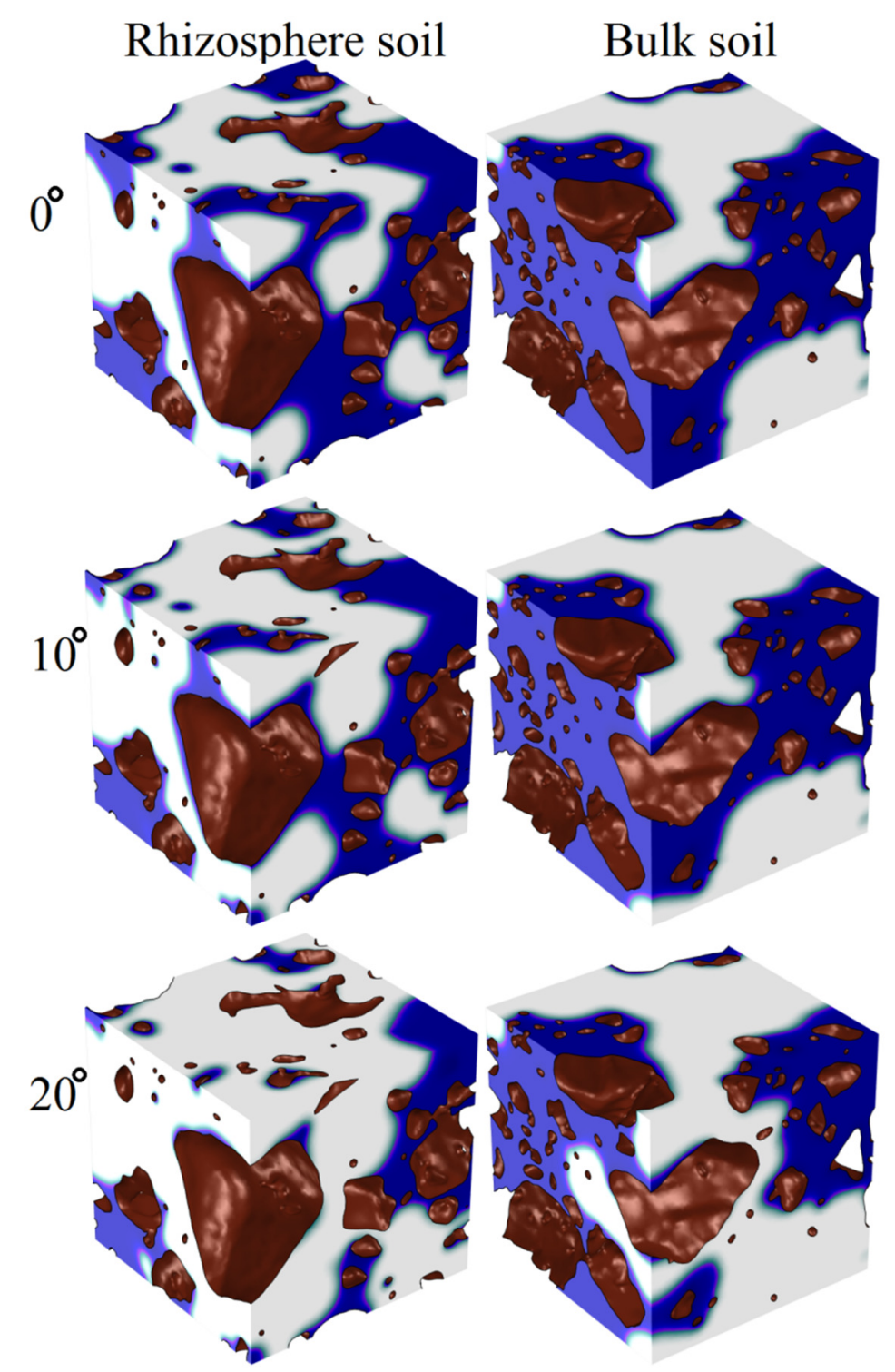

Figure 5: Soil pore water profiles (blue - water, brown - solid, white - air filled porespace) for the rhizosphere and bulk soil samples at $3.8 \mathrm{kPa}$. The left hand side images show the rhizosphere soil 1341 1342 samples, whilst the right hand side show the bulk soil samples. The top, middle and bottom images show the $0^{\circ}, 10^{\circ}$ and $20^{\circ}$ contact angles respectively. 

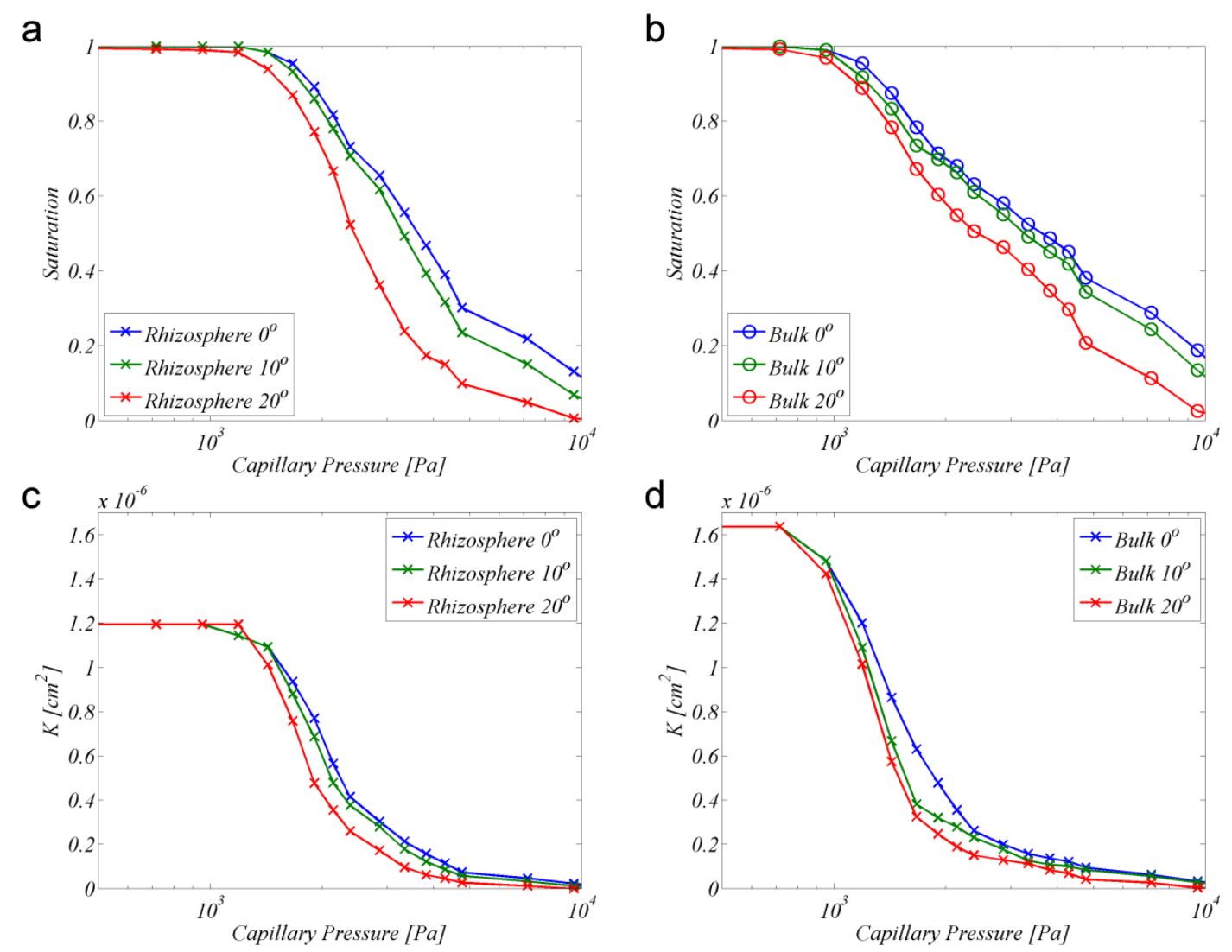

1345 Figure 6: Water release curves calculated for the rhizosphere (a and c) and bulk (b and d) soils at 1346 contact angles of $0^{\circ}, 10^{\circ}$ and $20^{\circ}$. 
1349 Table 1: Definition of scales considered in this review

\begin{tabular}{|l|l|c|}
\hline Scale & Features & Approximate size \\
\hline Nano-scale & Water-thin films & $<10 \mathrm{~nm}$ \\
\hline \multirow{2}{*}{ Micro-scale } & Root hairs & $\approx 10 \mu \mathrm{m}$ \\
\cline { 2 - 3 } & Mycorrhizal fungi & $\approx 5 \mu \mathrm{m}$ \\
\hline \multirow{2}{*}{ Macro-scale } & Roots & $\gtrsim 1 \mathrm{~mm}$ \\
\cline { 2 - 3 } & Soil continuum scale & $>1 \mathrm{~mm}$ \\
\hline
\end{tabular}

Table 2: Volume fractions of the different phases in classified CT images.

\begin{tabular}{|l|l|l|l|l|l|}
\hline & & Air & Water & Mixed & Solid \\
\hline Rhizosphere & Otsu & 0.03 & 0.33 & 0.35 & 0.29 \\
\cline { 2 - 6 } & WEKA & 0.04 & 0.34 & 0.33 & 0.29 \\
\hline Bulk & Otsu & 0.03 & 0.28 & 0.43 & 0.25 \\
\cline { 2 - 7 } & WEKA & 0.13 & 0.19 & 0.44 & 0.24 \\
\hline
\end{tabular}

Table 3: Effect of changing thresholds on pore volume fraction in segmented CT images.

\begin{tabular}{|l|l|l|l|l|}
\hline & \multicolumn{4}{|l|}{ Pore volume fraction } \\
\hline & Otsu & $\begin{array}{l}\text { Otsu } \\
\text { upper }\end{array}$ & $\begin{array}{l}\text { Otsu } \\
\text { lower }\end{array}$ & WEKA \\
\hline Rhizosphere & 0.71 & 0.72 & 0.69 & 0.71 \\
\hline Bulk & 0.75 & 0.77 & 0.68 & 0.76 \\
\hline
\end{tabular}

